\title{
Drug Release Studies of SC-514 PLGA Nanoparticles
} Toluleke Oloruntobi Famuyiwa ${ }^{* 1,2,3}$, Zoey Bowers ${ }^{1}$, Austin Bentley ${ }^{2,3}$, Davian Caraballo ${ }^{1}$, Paulynice Subtil ${ }^{1}$, James Kwasi Kumi Diaka ${ }^{1}$ and Waseem Asghar ${ }^{1,2}$

\section{Affiliation}

${ }^{1}$ Department of Biological Sciences, Florida Atlantic University, USA

${ }^{2}$ Department of Computer Engineering and Electrical Engineering and Computer Science, Florida Atlantic University, USA

${ }^{3}$ Department of Biological Sciences, Broward College, USA

*Corresponding author: Toluleke Oloruntobi Famuyiwa, Department of Biological Sciences, Florida Atlantic University, 777 Glades Road, Boca Raton, FL 33431, USA, E-mail: famuyiwatoluleke@gmail.com

Citation: Famuyiwa TO, Bowers Z, Bentley A, Caraballo D, Subtil P, et al. Drug release studies of SC-514 PLGA nanoparticles (2021) Pharmacovigil and Pharmacoepi 4: 1-21.

Received: Apr 15, 2021

Accepted: June 01, 2021

Published: June 14, 2021

Copyright: () 2021 Famuyiwa TO, et al. This is an open-access article distributed under the terms of the Creative Commons Attribution License, which permits unrestricted use, distribution, and reproduction in any medium, provided the original author and source are credited.

\begin{abstract}
A major problem associated with prostate cancer treatment is the development of drug resistance. The development of drug resistance often leads to prostate cancer metastasis and prostate cancer-targeted drug delivery systems can be utilized to address this problem. Traditional drug delivery systems have many challenges, including the inability to control the drug release rate, target site inaccuracy, susceptibility to the microenvironment, poor drug solubility, and cytotoxicity of chemotherapeutics to non-malignant cells. As a result, there is an urgent need to formulate and functionalize a drug delivery system that better controls drug release. This study was designed to quantify the release of SC-514 from SC-514 Polylactic-Co-Glycolic Acid (PLGA) nanoparticles and conjugate SC-514-PLGA coated nanoparticles with the NF- $\kappa \beta$ antibody, as well as fats. This study further explored new methods to quantify the release of SC-514 drug from the SC-514-PLGA coated nanoparticles after utilizing Liquid Chromatography-Mass Spectrometry (LC-MS) as the standard method to quantify SC-514 drug released. After quantification was completed, cell viability studies indicated that the ligand conjugated nanoparticles demonstrated a considerable ability to reduce tumor growth and SC-514 drug toxicity in the PC-3 cell line. The prepared drug delivery systems also possessed a significantly lower toxicity (P $<0.05$ ), bettered controlled-release behaviors in prostate cancer, and increased the solubility of SC-514 in comparison to free SC-514. SC-514 released from SC-514-PLGA, SC-514-PLGA-NF- $\kappa \beta A b$, and SC-514-PLGA-Fat nanoparticles, significantly inhibited tumor growth when compared to that of free SC-514. The anti-cancer therapeutic effects of SC-514 were improved through the encapsulation of SC-514 with a PLGA polymer. The functionalized SC-514-PLGA nanoparticles can further control burst release. The new methods utilized in this study for quantifying drug release, may prove to be as effective as the current standard methods, such as LC/MS.
\end{abstract}

Keywords: Drug, nanoparticles, Drug resistance, Drug release and Biomaterials.

Abbreviations: PLGA- Polylactic-Co-Glycolic Acid, LC-MS- Liquid Chromatography-Mass Spectrometry, EPR- Enhanced Permeability and Retention, PC- prostate cancer, MDR- Multidrug Resistance.

\section{Introduction}

Poly lactic-co-glycolic acid, referred to as PLGA, is one of the most successfully used biodegradable polymers used in controlled drug delivery systems [1-4]. Over the past 50 years, the development of biodegradable polymers has represented a revolution in medicine and has led to significant biotechnological advancements for drug delivery, biomaterials, tissue engineering, and medical device development. The development of these biodegradable polymers has been made possible through a unique collaboration between chemists, engineers, biologists, and physicians. One of the major driving forces for the development of polymeric drug delivery platforms has been the necessity of improving cancer therapeutics. Currently, anti-cancer drugs have short half-lives, nonspecific drug distribution throughout the body, and acute toxicity to nonmalignant cells [5].

For the treatment of prostate cancer, controlled-release nanodrugs delivery platforms have substantial advantages, compared to conventional treatments, because they can overcome pharmacological limitations such as drug resistance. Polymeric NP drug delivery systems possess the capacity for localized and sustained drug delivery, as well as the ability to improve the therapeutic index of various drugs. The numerous therapeutic advantages of polymeric drug delivery platforms can be attributed to their versatile nature and ability to control drug release [6-8].

A common endeavor in nanomedicine has been the encapsulation of NPs with PLGA polymer [9]. Polyesters, such as PLGA, have been approved by the FDA and EMA, and are generally well tolerated within the body $[10,11]$. Due to this, polyesters are the most commonly investigated class of biodegradable drug delivery systems [12]. Much of the current interest in NPs as drug delivery vehicles has arisen from the potential of NPs to increase pharmacokinetic activities and improve the safety profiles of the cargo (therapeutic drugs) in which they encapsulate. Numerous NP delivery system formulations are under clinical evaluation, while several have already been translated into clincical application and are available on the market [13,14]. Many of these nano formulations are being developed for oncological use because NPs 
can "passively" accumulate within tumors through a phenomenon known as Enhanced Permeability And Retention (EPR) effect [15]. NPs accumulate through EPR by exploiting defects in the neo vasculature endothelial junctions and impaired lymphatic drainage. Functionalizing the surface of NPs with targeting ligands can further enhance cellular uptake and tumor site retention through a concept known as "active" targeting [16]. NPs are promising new drug carrier systems due to their exceptional biocompatibility as well as their ability to control and sustain the release of drugs $[17,18]$.

The potential to solubilize poorly soluble therapeutic substances, reduce drug toxicity, prolong drug circulation time, control drug release kinetics, improve drug targeting, and enhance therapeutic efficacy through monitored drug delivery, has encouraged the continual expansion of this type of research [19-27]. NPs which possess the correct size, shape, and cell surface properties can systemically circulate for prolonged periods of time, "passively" target cancerous tumors through accumulation using the EPR effect, and locally release the drug to malignant cells [28-34]. NP drug delivery systems have promising potential for reducing the development of Multidrug Resistance (MDR) during prostate cancer treatment through controlled chemotherapeutic drug release at the site of the malignancy [25-27].

The intervention of nanoparticle drug delivery is needed because Prostate Cancer (PC) is the most commonly diagnosed male malignancy in the western world [35]. The development of drug resistance and progression to metastasis are common clinical implications of those who are actively managing PC. For PC to metastasize to distant sites throughout the body, PC cells must first migrate and invade neighboring tissue(s). Malignant cells, including PC cells, can acquire a migratory and invasive phenotype by various means including single cell and collective cell migration. Additionally, a motile, mesenchyme-like phenotype is often required for PC cell migration. To acquire this phenotype, polarity and epithelial characteristics (example, expression of E-cadherin homotypic adhesion receptor) frequently have to be lost as well, mesenchyme phenotypic characteristics (for example, cytoskeletal rearrangements, enhanced expression of proteolytic enzymes and other repertory of integrin's) have to be developed. The entire process is known as the Epithelial-To-Mesenchyme Transition (EMT).

One of the hallmarks of cancer is cellular invasion. Cellular invasion is defined by the movement of cells through a three-dimensional matrix, resulting in cellular environment remodeling. The essential components of cellular invasion are cellular adhesion, proteolysis of the ECM, and malignant cell migration. In-vitro studies on the migratory and invasive abilities of cells are useful tools for assessing the aggressiveness of solid tumors, including those of the prostate. The Trans well migration assay (a common in-vitro technique used to investigate the migratory behavior of PC cells) was introduced in this study as an alternative method for quantifying the amount of SC-514 released from the SC-514-PLGA NPs.

The NP encapsulation method utilized can influence the amount of drug released and the effectiveness of drug quantification method(s). The methodology and material used for encapsulating poorly soluble, fragile, or toxic compounds is vital for drug delivery. By bettering the efficacy of drug encapsulation in drug carrier particles, stronger therapeutic effect(s) and minimalized negative side effect(s) can be achieved [36]. As a result, examining the potentiality of new encapsulation materials and understanding the various drug-carrier interactions (the interaction between the drug and the encapsulating material) permits the development of new methods. Drug-carrier interactions have the ability to significantly increase the entrapment of the drug and, thus, are of further importance when considering drug design [36].
The construction of drug-controlled delivery systems for the treatment of various diseases, including cancer, is of significant research interest due to their facilitation of high therapeutic efficacy, avoidance of repeated drug administrations, and betterment of patient compliance $[37,38]$. Many drug-release systems are also sensitive to external stimuli such as temperature, $\mathrm{pH}$, magnetism, or electric fields [39-41]. These Stimuli-responsive drug carriers can release their encapsulated drug in a controlled manner compared to that of conventional drug delivery systems. Drug delivery systems encapsulated with polymers, including PLGA, have demonstrated the capacity for this controlled release performance [42-44]. The solubility of a drug is generally intrinsically related to the drug's particle size - as a particle becomes smaller, the ratio of surface area to volume increases. The larger surface area of small particles allows for greater interaction with the solvent, resulting in increased solubility [45].

Nano therapeutics can be exploited for the delivery of poorly soluble compounds, such as SC-514, through intravenous drug administration. SC-514 is a relatively new, small molecule drug that has potential therapeutic use for the treatment of prostate cancer [46]. However, due to the poor solubility of the compound, SC-514 is classified as a class IV or class II drug, according to Bio Pharmaceutics Classification Systems (BCS) classification [47]. NPs encapsulated with PLGA are potentially compelling delivery systems for optimizing the conditions for SC-514 drug delivery, solubility, and controlled release into tissues and cells, by protecting the drug from oxygen and acids [48]. In this study, PLGA encapsulated NPs were utilized to improve the bioavailability of the poorly water-soluble, SC-514.

NPs that have accumulated at the target site require changes to their drug release rate in order to improve their efficacy [49-51]. When formulating a NP carrier for a drug it is important to consider optimizing drug loading, and quantifying the amount of drug that remain associated with the carrier over various points in time [52]. NP-drug formulation performance is partially dependent on the efficiency of drug loading, which is often determined by the Encapsulation Efficiency (EE), EE is the percentage or fraction of drug that is associated with the NP carrier after particle manufacture and during drug release. The time course of NP drug release is an additional principal factor because it establishes the amount of free drug available over time.

The availability of free drug is essential for therapeutic effect and, occasionally, for modifying the drug's toxicity profile [53,54].The in-vitro drug release profiles (drug loading and drug release efficiency), measured in bio-relevant medium, can provide substantial predictive evidence for in-vivo behavior of the encapsulated drug as well as the mechanism(s) of drug release $[52,55]$. Insight into the mechanism(s) of drug release can further be utilized during formulation parameter optimization to achieve the desired release rate properties, such as NP surface area. Thus, investigating the in-vitro drug release kinetics of NP-drug formulations is essential for proper nanoparticle design and invitro-in-vivo correlations.

The drug release mechanisms of NP carriers can be chosen based on the biological differences between the tumor microenvironment and healthy tissue; These differences include lower $\mathrm{pH}$, lower oxygen levels, increased matrix metalloproteinase enzymatic activity, and variance in NF- $\kappa \beta$ activation [56,57]. In the tumor microenvironment, NF- $\kappa \beta$ is the primary transcription factor involved in immune system function regulation and plays a critical role in cancer development and progression [57]. Additionally, NF- $\kappa \beta$ regulates various biological activities including cell proliferation and differentiation. Activation of NF- $\kappa \beta$ is correlated with proliferation of hematopoietic stem cells and resistance to apoptosis. These contrasting activities seemingly occur through a 
balance of the transcription factor's biological and biochemical functions $[58,59]$. Furthermore, NF- $\kappa \beta$ has a well-defined role in oxidative stress as it increases Nitric Oxide (NO) through Inducible Nitric Oxide Synthase (iNOS) activation. Although acute NO production can trigger apoptosis, and the process of iNOS activation is often regarded as part of NF- $\kappa \beta$ 's pro-apoptotic function, the continuous production of NO, due to constant activation of NF- $\kappa \beta$, may potentially inhibit apoptosis [59-62].

Up regulation of anti-apoptotic NF- $\mathrm{KB}$ target genes have been reported in various types of malignant tumors. Among these genes are, Inhibitors of Apoptosis (IAPs), FLICE-like inhibitory protein (FLIP), and members of the B cell-lymphoma 2 (Bcl-2) family that inhibit apoptosis [63-65]. NF- $\mathrm{BB}$ activation has also been associated with the up regulation of enhancers involved in cell proliferation (i.e., Cyclic D1 and Cellular Myelocytomatosis (c-myc)) and cell adhesion molecules, as well as angiogenic factors that enhance malignant cell engraftment (i.e., Intercellular Adhesion Molecule 1 (ICAM-1) and Vascular Endothelial Growth Factor (VEGF)) [6368].

Furthermore, NF- $\mathrm{kB}$ activation regulates the expression of heme oxygenase-1 (HO-1), a catabolic enzyme that acts on the free heme group [69]. Enhanced free heme catabolism (increased HO-1 activity) has a protective role against apoptosis because free heme is known to cause damage to the lipid bilayer of the cellular membrane [70]. In cancers, the up regulation of HO-1 has been shown to aid in evading apoptosis induced by Tumor Necrosis Factor- $\alpha$ (TNF- $\alpha$ ), as well as apoptosis induced by chemotactic drugs [64]. Due to the implications of NF- $\mathrm{KB}$ in cancer cell survival and progression, this study investigated the potential impact of NF- $\mathrm{KB}$ signaling pathway activation on PLGA-NP drug release, within the microenvironment of PCa cells. To accomplish this, NF- $\kappa \mathrm{B}$ antibodies (conjugant) were conjugated to the PLGA-NP carrier systems.

Another factor utilized to investigate the drug release of SC-514 in this study was fat accumulation around PLGA-NP carrier systems. This was done because obesity is associated with numerous chronic medical conditions and diseases, including prostate cancer. In almost every country where detailed data is available, obesity has become more pervasive [71]. Evidence has suggested that the prevalence of obesity has been increasing for over one hundred years, however, in the United States, there appears to be an accelerated rate of increase beginning around the 1980s [72-76].

Obesity has become an epidemic as one in six American adults were considered to be obese 20 years ago; yet one in three American adults are considered to be obese today [77-82]. The past twenty years of increased obesity prevalence has occurred throughout every age, race, sex, and socioeconomic group, and is correlated to a decrease in physical activity and an increase in poor dietary consumption [83-84]. Further, fat deposition has been suggested to influence bioavailability and effect drug release in the tumor microenvironment [85-86]. Due to this, the potential impact of fat accumulation on the drug release profile of SC-514 from SC-514PLGA-Fat NPs was investigated in this study.

Surface modification of nanoparticles is a key requisite for extending circulation half-life and promoting localization. For example, nanoparticles coated with a highly cationic polymer have been used to enhance cellular uptake or open intercellular tight junctions $[87,88]$. Foliate receptors over-expressed on the surface of malignant human cells were targeted by grafting foliate on the surface of nanoparticles [19]. Studies revealed that the nanoparticles attained a 10 -fold higher affinity for the surface foliate binding protein than free foliate [89]. Researchers reasoned that the multivalent form of foliate on the nanoparticle surface interacted strongly with foliate receptors, which are often present in clusters on the surface of cancer cells, like the clustering of ICAM-1 during T- cell adhesion. Finally, research efforts are ongoing to improve nanoparticle performance in-vivo by extending nanoparticle circulation and limiting interaction with blood constituents [90] and in-vitro. However, it is not well understood how the kinetics of such a drug delivery system will proceed [17] especially with SC-514 loaded PLGA nanoparticles and conjugation of SC-514 loaded PLGA nanoparticles with other molecules such as NF-KBAb and Fat. This conjugation may alter the Encapsulation Efficiency (EE) and the drug release profile.

The measurement of both $\mathrm{EE}$ and in-vitro drug release from colloidal particles typically requires methods for the rapid physical separation of particles from their surrounding dispersion medium to enable real-time determination of the proportion of free drug. For large particles this may be achieved by a simple filtration approach. However, separation can be challenging for nanoparticles due to their small size [91]. Most methods for the measurement of encapsulation and in-vitro release separate the particles from the medium in which they were dispersed and rely on the quantification of the 'free' fraction of drug to indirectly measure the nanoparticlebound fraction. Numerous methods for the separation of free and nanoparticle-associated drug are dialysis-based methods, ultracentrifugation, centrifugal ultrafiltration and pressure ultrafiltration [91-96].

After SC-514 was released from SC-514-PLGA nanoparticles, Liquid Chromatography-Mass Spectrometry (LC-MS) was utilized as the standard method to quantify the SC-514 drug released from SC-514-PLGA nanoparticles. Liquid chromatography-tandem mass spectrometry (LC-MS/MS) has seen enormous growth in routine toxicology laboratories. LC-MS/MS offers significant advantages over other traditional testing, such as immunoassay and gas chromatography-mass spectrometry methodologies. Major strengths of LC-MS/MS include improvement in specificity, flexibility, and sample output when compared with other technologies [97]. The LC-MS/MS steps usually involve reverse-phase chromatography using bonded phases and methanol-water gradient solvent systems, since these are more compatible with the mass spectrometry steps [98]. This current study explored other inexpensive methods such as colony assay, wound healing assay, and trans well migration and invasion assay for the quantification of SC-514 release from SC514-PLGA nanoparticles.

\section{Materials and Methods}

\section{Determination of drug solubility in release media (10 mM phosphate buffered saline (pH 7.4) supplemented with $10 \%(\mathrm{v} / \mathrm{v})$ of FBS and $1 \%(\mathrm{v} / \mathrm{v})$ PenStrep ${ }^{\circledR}$}

Prior to the release experiments the thermodynamic solubility of SC-514 drug in release media was tested. For this purpose, $100 \mathrm{mg}$ the SC-514 drug was added to $3 \mathrm{~mL}$ of the releasing medium and incubated at $37^{\circ} \mathrm{C}$ for 24 hours. The release medium was composed of a $10 \mathrm{~mm}$ phosphate buffered saline ( $\mathrm{pH}$ 7.4) supplemented with $10 \%(\mathrm{v} / \mathrm{v})$ of FBS and 1\% (v/v) Pen Strep ${ }^{\circledR}$ to avoid microbial growth. The mixture of the SC-514 drug and release medium was collected in a micro centrifuge tube for centrifugation. A solubility study was carried out by using centrifugation to separate the particulate fraction of SC-514 drug in the release medium.

\section{Conjugation of SC-514 loaded PLGA nanoparticle with NF-KB antibody}

$10 \mu \mathrm{g}$ of the NF-KB was added to $200 \mathrm{mg}$ PLGA polymer for the Nano-formulation. The nanoparticles were formulated with tween 80 as the surfactant optimizing the nanoparticles for NF- $\mathrm{KB}$ antibody ligand conjugation. [99]. The final concentration of antibody in the NP solution was approximately $0.06 \mu \mathrm{g} / \mathrm{mL}$ 


\section{Functionalization of SC-514-PLGA nanoparticles with fats and oil}

(melted animal fat was utilized) was carried out using trimethylphenylammonium chloride (199168-100G) as cationic surfactant (substances in which the hydrophilic, or water-loving, end contains a positively-charged ion, or cation) ionically bonding the fats and oil to the surface of the nanoparticles as adapted from previous studies [100-104].

\section{Dialysis method of drug release}

The effective drug concentration within the nanoparticle provides the driving force for release from the particle in the release media (phosphate buffered saline ( $\mathrm{pH}$ 7.4) supplemented with $10 \%(\mathrm{v} / \mathrm{v})$ of FBS). In-vitro release kinetics of SC-514-PLGA, SC-514-PLGANF-KBAb, and SC-514-PLGA-Fat was investigated in this study using dialysis bag method. Typically, SC-514-loaded nanoparticle suspension $(1.0 \mathrm{~mL})$ or drug solution with the equivalent drug concentration was enclosed in a dialysis bag (MWCO $12 \mathrm{kDa}$ ) and then placed in $200 \mathrm{~mL}$ of $\mathrm{pH} 7.4$ phosphate buffered saline solution (supplemented with $10 \%(\mathrm{v} / \mathrm{v})$ of FBS). The release medium was replaced with fresh buffer every 24 hours. The entire system was kept at $37^{\circ} \mathrm{C}$ with continuous magnetic stirring.

\section{SC-514 PLGA Nanoparticles Instrument Settings}

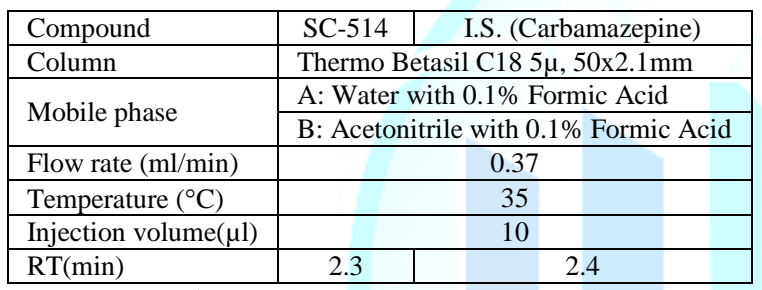

Table 1: LC (Shimadzu UFLC XR) conditions.

\section{Quantification of SC-514 released by LC-MS analysis of SC-514 PLGA nanoparticles}

At 24 hours time intervals, $30 \mu \mathrm{L}$ of aqueous solution was withdrawn from the release medium and the SC-514 concentration was assayed using ABSciex 5500 mass spectrometer. A standard curve was utilized to determine the unknown quantity of SC-514 released in the aqueous solution. The sample was put back to the release medium after the measurement. For determining release kinetics of SC-514-PLGA suspension, a dialysis bag $(12 \mathrm{kDa}$ MWCO) was used to enclose the sample $(5 \mathrm{~mL})$. The sealed dialysis bag was then placed in a USP apparatus 2 containing $150 \mathrm{~mL}$ of $\mathrm{pH}$ 7.4 PBS at $37^{\circ} \mathrm{C}$ with a paddle rotating at $100 \mathrm{rpm}$. At interval of 1 day for 30 days, $30 \mu \mathrm{L}$ of release medium was taken out and drug concentration was measured by HPLC and MS/LC. The $30 \mu 1$ of each sample that was removed was added to $70 \mu \mathrm{l}$ of acetonitrile containing carbamazepine as the internal standard. Samples were compared to a standard curve prepared in RPMI-1640 medium.

\begin{tabular}{|c|c|c|}
\hline $\begin{array}{c}\text { Time } \\
(\mathrm{min})\end{array}$ & $\begin{array}{c}\text { Mobile } \\
\text { phase A (\%) }\end{array}$ & $\begin{array}{c}\text { Mobile phase } \\
\mathrm{B}(\%)\end{array}$ \\
\hline 0.2 & 90 & 10 \\
\hline 0.5 & 90 & 10 \\
\hline 2 & 5 & 95 \\
\hline 3 & 5 & 95 \\
\hline 3.8 & 90 & 10 \\
\hline 5 & 90 & 10 \\
\hline
\end{tabular}

Table 2: Gradient elution conditions.

All samples were filtered through a 0.2-micron prior to HPLC and MS/LC analysis. HPLC and MS/LC parameters are provided in the tables below. All the release experiments were repeated 3 times and the mean \pm standard deviations were reported

\begin{tabular}{|c|c|c|}
\hline Compound & SC-514 & I.S. (Carbamazepine) \\
\hline MRM(+) & $225.3 / 135.8$ & $237.2 / 194.1$ \\
\hline Collision Gas & \multicolumn{2}{|r|}{7} \\
\hline Curtain GAS & \multicolumn{2}{|r|}{36} \\
\hline Ion Source Gas 1 & \multicolumn{2}{|r|}{40} \\
\hline Ion Source Gas2 & \multicolumn{2}{|r|}{40} \\
\hline Ion Spray Voltage & \multicolumn{2}{|r|}{5500} \\
\hline Temperature $\left({ }^{\circ} \mathrm{C}\right)$ & \multicolumn{2}{|r|}{500} \\
\hline Collision Energy & 40 & 26 \\
\hline $\begin{array}{c}\text { Declustering } \\
\text { Potential }\end{array}$ & 70 & 136 \\
\hline Entrance Potential & \multicolumn{2}{|r|}{10} \\
\hline $\begin{array}{c}\text { Collision Cell Exit } \\
\text { Potential }\end{array}$ & \multicolumn{2}{|r|}{14} \\
\hline
\end{tabular}

Table 3: MS (API5500) conditions.

\section{Calculation of Encapsulation Efficiency}

The encapsulation efficiency was calculated according to a method reported previously [105]. The drug encapsulation efficiency was calculated based on the equation: The drug encapsulation efficiency $(E E)=m_{2} / m_{1} \times 100 \%$.

Where $\mathrm{m}_{1}$ denoted the weight of SC-514 drug initially added, $\mathrm{m}_{2}$ was the weight of the drug embedded within the particles which was calculated according to the standard curve of the drug concentration versus absorbance from HPLC and MS/LC analysis. We analyzed SC-514 PLGA nanoparticles drug release profiles via other methods that are more cost-effective than HPLC and LC-MS/MS quantitation method. These methods are the wound closure assay; trans well cell migration and invasion assay, and colon genic assay. These assays were performed as described below.

\section{Cell Culture Wound Closure Assay}

Prostate cancer cells were detached from the tissue culture plate using $0.25 \%$ Trypsin-EDTA solution. Centrifugation was performed in a $15 \mathrm{ml}$ conical tube to pelletize the prostate cancer cells, the supernatant was aspirated, and cells were re-suspended in culture media. 100,000 cells were seeded in each well of the 6-well plate for $100 \%$ confluence in 24 hours. A $200 \mu$ pipette tip was utilized to make a wound in the plate by pressing the $200 \mu \mathrm{l}$ pipette tip firmly against the top of the tissue culture plate and swiftly make a vertical wound down through the cell monolayer in a biosafety hood. The media and cell debris were aspirated.

Adequate culture media was added to cover the bottom of the well in a manner that avoided detaching additional cells. Following the generation and inspection of the wound an initial picture was taken. -The tissue culture plate was placed in an incubator set at $37^{\circ} \mathrm{C}$ temperature and 5\% CO2 concentration. The plate was removed from the incubator every 24 hours and placed under an inverted microscope to take a snapshot picture and to check for wound closure. To analyze the results of snapshot pictures, the distance of one side of the wound to the other was measured using a scale bar.

For the wound assay, a $200 \mu 1$ pipette tip was utilized to make the wound, although a different sized pipette tip may be used to make the wound size that is desired. A minimum force was utilized to make a wound on the culture flask. If excessive force was utilized against the tissue culture plate with the pipette tip, the surface of the culture flask may be damaged. A damaged flask will interfere with the result. In other types of culture flasks, the wound is in a pre-cast form.

Transwell Cell Invasion Assay

Prostate cancer cells were detached from the tissue culture plate using $0.25 \%$ Trypsin-EDTA solution in a biosafety hood, prostate 
cancer cells were then pelletized by centrifugation, and the existing media was aspirated leaving the pelleted cells. The cells were resuspended in serum free cell culture media containing $0.1 \%$ BSA (bovine serum albumin). $100 \mu$ of cell solution at the concentration of 10,000 cells per well was seeded on top of the filter membrane in a trans well insert and incubated for $10 \mathrm{~min}$ at $37{ }^{\circ} \mathrm{C}$ and $5 \% \mathrm{CO}_{2}$ to allow the cells to settle down. The pore size of the Trans well membrane was $4 \mu \mathrm{m}$.

At another time, the Trans well migration assay was modified to perform the cell invasion assay. Extracellular matrix (ECM) materials were on top of the transwell membrane. Cells were added on top of the ECM (Matrigel). Matrigel was thawed and liquefied on ice, and then 30-50 $\mu 1$ of Matrigel was added to a 24-well Trans well insert and solidified in a $37^{\circ} \mathrm{C}$ incubator for $15-30$ minutes to form a thin gel layer. Cell solution was added on top of the Matrigel coating to simulate invasion through the extracellular matrix. The Trans well cell invasion assay measures both cell chemo taxis and the invasion of cells through the extracellular matrix, a process that is commonly found in cancer metastasis.

Briefly, a pipette was utilized to add $600 \mu \mathrm{l}$ of Monocyte Chemotactic Protein 1 (MCP-1), also known as CCL2 (PIRP8648) into the bottom of the lower chamber of a 24-well plate at $0.1 \mathrm{mg} / \mathrm{mL}$ of sterile water. The chemo-attractant was added without moving the Trans well insert to avoid generating bubbles. The chemo-attractant liquid in the bottom well contacted the membrane in the upper well to form a chemotactic gradient. The Trans well insert well was removed from the plate. A cotton-tipped applicator was used as many times as needed to carefully remove the media and remaining cells that had not migrated from the top of the membrane without damaging it. $600 \mu \mathrm{l}$ of $70 \%$ ethanol was added into a well of a 24-well plate. The transwell insert was placed inside the $70 \%$ ethanol for $10 \mathrm{~min}$ to allow cell fixation. The transwell insert was removed from the 24-well plate and a cotton-tipped applicator was utilized to remove the remaining ethanol from the top of the membrane. The transwell membrane was air- dried for 10-15 min. $700 \mu 1$ of $0.2 \%$ crystal violet $(0.1 \%)$ was added into a well of a 24-well plate. The membrane was positioned into the well for staining and incubated at room temperature for 5-10 $\mathrm{min}$.

The crystal violet was gently removed from the top of the membrane with a pipette tip or cotton tipped applicator. The membrane was dipped into distilled water as many times as needed to remove the excess crystal violet. The transwell membrane was allowed to airdry. An inverted microscope was utilized to count the number of cells in different fields of view to get an average sum of cells that have migrated through the membrane toward the chemo-attractant $\left(\mathrm{CCL}_{2}\right)$ and attached on the underside of the membrane.

Matrigel (BD Biosciences, NJ) was obtained to cover the bottom membrane of transwell chambers ( 24 holes, Corning Inc., NY), to measure the invasive ability of cells. The mixture of Matrigel and medium at the proportion of 1:2 at $50 \mu 1$ was enclosed by each transwell membrane. The upper chamber was inoculated with $2.5 \times$ 104 cells, while the serum, growth factors as well as chemokine were placed into the lower chamber and cultured in $5 \% \mathrm{CO}_{2}$ at $37^{\circ} \mathrm{C}$ for $3 \mathrm{~h}$. Then, chambers were stabilized with paraformaldehyde for $20 \mathrm{~min}$ and $500 \mu 10.1 \%$ crystal violet was added for 10 mins before being washed out. After air drying, stained cells were photographed and counted under the light microscope $(100 \times)$ in four randomly selected fields. Transwell assays were performed as previously described. Images of 4 different fields were acquired for each membrane with an optical microscope using a $20 \times$ magnification. Each one of the 3 independent experiments were repeated in triplicates.

An invasion assay was created by blocking the pores in the membrane with a gel composed of an extracellular matrix that is meant to mimic the typical matrices that tumor cells encounter during the invasion process in-vivo. By placing the cells on one side of the gel and a chemo attractant on the other side of the gel, invasion is determined by counting those cells that have traversed the cell-permeable membrane having invaded towards the higher concentration of chemo attractant [106].

For transwell cell migration and transwell invasion assay, the goal of this component of the research was to determine how SC-514 drug released influenced proliferation, invasion, and migration of human prostate cancer cells. The level of proliferation of human prostate cells was measured by counting the number of prostate cancer cells that migrated through the filter. This study provided an overview of the adaptations to the Transwell migration protocol to study the invasive capacity of prostate cancer cells after release of SC-514 drug. Generally, incubation time of the cells is dependent on cell type and the chemo-attractant being used. In this study we utilized $\mathrm{CCL}_{2}$ (Monocyte chemo attractant protein-1, MCP-1) as the chemo attractant. The migrated PC-3 cells attached to the other side of the membrane. A previous study utilized alizarin red to stain the migrated cells [107]. In this study, we used crystal violet for staining the migrated PC-3 cells.

\section{Colonigenic assay}

The medium, PBS and trypsin were warmed at $37^{\circ} \mathrm{C}$. Trypsinization was utilized to harvest cells from a donor culture. To detach cells from the plastic, the overlying medium was removed, and cells were washed with PBS. PBS was removed and replaced by a trypsin solution to produce a single-cell suspension.

The inverted microscope was utilized to investigate when cells started to round up, indicating detachment from the culture dishes. The cells were re-suspended in medium to inhibit trypsinization. Sufficient volume of medium (more than $3 \mathrm{X}$ the volume of trypsin) supplemented with serum was added to neutralize the trypsin solution. The cells were detached by the medium with the cells pipetting up and down

The cells were counted such that an accurate number of cells were obtained. The cells counted were plated to obtain the correct data for Plating Efficiency (PE).

The cell suspension was diluted into the desired seeding concentration and seeded into flasks or plates as desired.

Cells were plated before treatment. Cells were harvested from a stock culture and plated at appropriate dilutions into (cluster) dishes. After attachment of the cells to the dishes $(2 \mathrm{~h})$, the cells were treated with SC-514 drug release from SC-514-PLGA. A dialysis bag served as a separation barrier between the SC-514 PLGA nanoparticles and the PC-3 cells in the culture disc. The treatment was performed before cells started replicating.

The cells were transferred to the test dishes in triplicate. The dishes were placed in an incubator and left there until the cells in control dishes formed sufficiently large clones. To fix and stain the colonies, the medium above the cells was removed. The cells were rinsed carefully with PBS. The PBS was removed and 2-3 ml of a mixture of $6.0 \%$ glutaraldehyde and $0.5 \%$ crystal violet was added. The mixture was left for $30 \mathrm{~min}$. The glutaraldehyde crystal violet mixture was removed carefully after $30 \mathrm{~min}$ and rinsed with tap water. Afterwards, the dishes with colonies were left to air dry at room temperature. Cloned cell numbers surpassing 50 were counted [108]. Colony counts were performed utilizing a stereomicroscope and a counter. For the Colonigenic assay: The dilutions were performed before seeding the correct number of cells. The treatment was performed before cells started replicating; otherwise, the numbers of cells per dish would increase, yielding more colonies. After treatment, the dishes were placed in an incubator and left there 
for approximately 2 weeks (a time equivalent to at least six potential cell divisions).

Confocal microscopy indicating cellular uptake of SC-514 loaded PLGA nanoparticles by PC-3 prostate cancer cells and cord blood cells

The cellular distribution and localization of NPs in prostate cancer cells were assessed by confocal microscopy. To detect fluorescent signals in cellular uptake studies, FITC-BSA was used instead of BSA. An equivalent amount of FITC-BSA was used to fabricate the NPs. The cellular distribution of FITC-BSA-loaded NPs in prostate cancer cells was evaluated by confocal microscopy. Cells were seeded onto culture slides (BD Falcon, Bedford, MA, USA) at a density of $1.0 \times 105$ cells per well $\left(1.7 \mathrm{~cm}^{2}\right.$ surface area per well $)$ and incubated for $24 \mathrm{~h}$ at $37^{\circ} \mathrm{C}$. FITC-BSA $(50 \mu \mathrm{g} / \mathrm{mL})$ solution and FITC-BSA $(50 \mu \mathrm{g} / \mathrm{mL})$-loaded NPs were incubated for $2 \mathrm{~h}$ at $37^{\circ} \mathrm{C}$, after which the cells were washed with PBS (pH 7.4) at least three times and fixed with a $4 \%(\mathrm{v} / \mathrm{v})$ formaldehyde solution for $10 \mathrm{~min}$. The cell culture slides were dried to eliminate the liquid content and treated with VECTASHIELD mounting medium, including 4',6diamidino-2-phenylindole (DAPI), to stain the nuclei of the prostate cancer cells and prevent fading. The intracellular fluorescence signals of FITC-BSA in NPs were monitored by confocal microscopy (Nikon A1R Confocal System w/SIM).

Prostate cancer cells were seeded onto 6-well plates at a density of $6.0 \times 105$ cells per well. After incubating for $24 \mathrm{~h}$ at $37^{\circ} \mathrm{C}$, aliquots of the FITC-BSA solution and the NP dispersion containing FITCBSA (corresponding to $50 \mu \mathrm{g} / \mathrm{mL}$ concentrations) were incubated for $2 \mathrm{~h}$. The cells were washed with PBS (pH 7.4) and collected. The cell pellets were resuspended with PBS containing FBS (2\%, v/v). The cellular accumulation efficiency was represented as the counted cells according to the fluorescence intensity.

\section{Investigation of time-dependent cellular uptake of SC-514-PLGA nanoparticles}

Immunofluorescence and confocal microscopy: Prostate cancer cells (80\% confluence) were incubated from the apical side with 0.5 $\mathrm{mg} / \mathrm{ml}$ suspension of PLGA nanoparticles loaded with 6-coumarin at $37^{\circ} \mathrm{C}$, and then washed three times with ice-cold BRS buffer. Cells were then fixed with $4 \%$ paraformaldehyde in PBS solution for 30 min, permeabilized using $0.5 \%$ Triton-X 100 in water for $15 \mathrm{~min}$, blocked with $10 \%$ bovine serum albumin (BSA) in PBS solution for $30 \mathrm{~min}$, and incubated with mouse monoclonal antibody (BD Biosciences, Lexington, KY) against either clattering $\mathrm{HC}$ or caveolin-1 for 2 hours. Cells were then washed several times with PBS and incubated for 1 hour with Rhoda mine-labeled goat antimouse secondary antibody. Finally, the cell filter was cut and mounted on a glass slide using a Prolong ${ }^{\mathrm{TM}}$ anti-fade mounting kit (Molecular Probes, Eugene, OR) and viewed under a confocal microscope (Nikon A1R Confocal System w/SIM) using both FITC (wavelength 450-490 $\mathrm{nm}$ ) and Rhoda mine filters (wavelength 550$570 \mathrm{~nm})$.

\section{In-vitro anti-tumoral activity of SC-514 loaded PLGA nanoparticles on PC-3 cells}

The cytotoxic activity of SC-514 treatment on prostate cancer cells was evaluated using free SC-514, SC-514-PLGA-NF-KBAb, and SC-514-PLGA-fat nanoparticles, by assessing the morphology or structural characteristics of the cells utilizing inverted microscopy. Cells were incubated with the drug concentrations of SC-514 released from the nanoparticle formulations after encapsulating 200 $\mu \mathrm{M}$ of SC-514 in each of the nanoparticle formulations.

The incubation was evaluated for $48 \mathrm{~h}$ for all the nanoparticle formulation treatments. PC-3 cells were exposed to the free SC-514 treatments and SC-514 released from PLGA nanoparticle treatments for 6 days.

\section{Cytotoxicity of NPs on cord blood cells}

Cord blood cells (from Dr. Hartmann) were cultured in RPMI containing $10 \%(\mathrm{v} / \mathrm{v})$ heat inactivated FBS, $1 \%(\mathrm{v} / \mathrm{v})$ penicillin $(100$ $\mathrm{U} / \mathrm{mL})$, and streptomycin $(0.1 \mathrm{mg} / \mathrm{mL})$ in $95 \%$ relative humidity and a $5 \% \mathrm{CO} 2$ atmosphere at $37{ }^{\circ} \mathrm{C}$. The toxicity of all the nanoparticle treatments (SC-514-PLGA, SC-514-PLGA-NF-KBAb, SC-514PLGA-Fat ) was assessed in cord blood cells by a colorimetric method using a tetrazolium compound [3-(4,5-dimethylthiazol-2yl)-5-(3-carboxymethoxyphenyl)-2-(4-sulfophenyl)-2H-tetrazolium, inner salt; MTS]. Cells at a density of $1.0 \times 104$ cells per well were seeded into 96-well plates. After incubating for $48 \mathrm{~h}$, SC-514 released from the nanoparticle treatment at various concentrations was added to cells, and the cells were incubated for $48 \mathrm{~h}$ at $37^{\circ} \mathrm{C}$.

\section{Immunofluorescence assay to investigate the expression of MDR proteins in PC-3 cells}

This study utilized the immunofluorescence assay to investigate the expressing of MDR proteins after treatment with free SC-514 and SC-514-PLGA nanoparticles. P-glycoprotein in PC-3 cells was tested for reactivity with p-170 antibody by indirect immunofluorescence studies. During these immunofluorescence studies only surface components of viable prostate cells are recognized [109].

Briefly, PC-3 prostate cancer cells were cultured at 2500 cells $/ \mathrm{ml}$ in 96 well plates. These cells were treated with free SC-514 and SC514-PLGA nanoparticles drug for $48 \mathrm{~h}$. After $48 \mathrm{~h}$ PC-3 prostate cancer cells were adjusted to a concentration of $1 \times 106 \mathrm{cells} / \mathrm{ml}$ in PBS and $100 \mu$ of the cell suspension was aliquoted into each of two Eppendorf tubes. A volume of $100 \mu 1$ antibody (1 in 100 dilution of antibody in PBS) was added to one tube and $100 \mu \mathrm{l}$ of control (diluted 1 in 100 in PBS) was added to the other. The tubes were mixed and incubated for $30 \mathrm{~min}$ at $4{ }^{\circ} \mathrm{C}$. The primary antibody was removed by centrifugation of cells at $1000 \mathrm{rpm}$ for $5 \mathrm{~min}$. The cells were washed three times with PBS using the same procedure and $100 \mu \mathrm{l}$ of Goat anti-Mouse $\operatorname{IgG}, \operatorname{IgM}(\mathrm{H}+\mathrm{L})$ Secondary Antibody, FITC (Life Technologies Corporation, catalogue number A11059 Lot\# 1910746) diluted 1 in 50 in PBS was added. The tubes were mixed and incubated for $30 \mathrm{~min}$ at $4{ }^{\circ} \mathrm{C}$ after which the secondary antibody was removed, and the cells were washed as mentioned previously. Each cell pellet was re-suspended in PBS and mounted on a slide for observation under confocal microscopy (Nikon A1R Confocal System w/SIM).

\section{Results}

Our previous study indicated that the methodology of nanoparticle preparation allowed the formation of spherical Nano metric particles (average diameter $49.9 \mathrm{~nm}$ ), homogeneous and negatively charged particles which are suitable for intravenous administration. Our previous study demonstrated that the incorporation of SC-514 in nanoparticles was effective, based on microscopic study (Scanning Electron Microscopic) [110]. In this study, SC-514-PLGA was conjugated with NF-KB antibody (NF-KBab) and Fat. Drug release of SC-514-PLGA, SC-514-PLGA-NF-KBAb, and SC-514-PLGAFat nanoparticles was investigated.

The result of the centrifugation experiment indicated that SC-514 has a poor solubility in the release medium. Hence, this study was conducted to evaluate the impact of increased solubility on the anticancer activity of SC-514 drug. The in-vitro anti-tumoral activity of the nanoparticles formulated (SC-514-PLGA, SC-514-PLGA-NF$\mathrm{KBAb}$ and SC-514-PLGA-Fat) was assessed using PC-3 human prostate cancer cell line (Figure 18 and Figure 19) and noncancerous cord blood cells (Figure 16 and Figure 17). The results of the in-vitro anti-tumoral activity of free SC-514 and SC-514 released from the nanoparticle formulations (SC-514-PLGA, SC- 
514-PLGA-NF-KBAb, and SC-514-PLGA-Fat) on PC-3 cells and cord blood cells were compared.

The MTT assay results demonstrated that incorporation of SC-514 in PLGA nanoparticles strongly enhanced the cytotoxic effect of SC-514 drug as compared to the anti-cancer effect of free SC-514 on PC-3 cells (Figure 18 and Figure 19) and the anti-cancer effect of free SC-514 on cord cells (Figure 16 and Figure 17). The inhibitory effects were more observable for prolonged incubation times when the cells received prolonged exposure to SC-514 drug. Importantly, the drug encapsulation efficiency was measured to be over $89 \%$ for SC-514-PLGA nanoparticles. SC-514 drug exhibits obvious encapsulation responsive release (Figure 2).

\section{Drug Release Analysis from LC/MS Drug Release Analysis Graph from LC/MS}

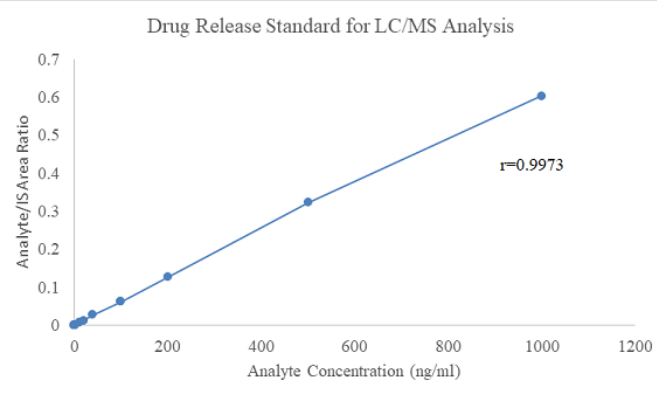

Figure 1: The kinetic model that best fits the dissolution data was evaluated by comparing the correlation coefficient $(\mathrm{r})$ values obtained in various models. The model that gave a higher ' $r$ ' value $(r=0.9973)$ is considered as the best fit model and is shown in this figure.

Based on the extremely high $r$ value $(r=0.9973)$ from the graph above, this study utilized the zero-order model for the drug release study. $30 \mu 1$ of aqueous solution containing released SC-514 was collected for each sample from day 1 to day 30 . The cumulative amount released vs. time was plotted (Figure 2) by calculating the amount of drug that permeated the membrane, which is equal to the amount of drug in the receiver at the sampling time plus the amount in the samples that was assayed then discarded.

\section{SC-514 Drug Release Studies from PLGA Nanoparticles}

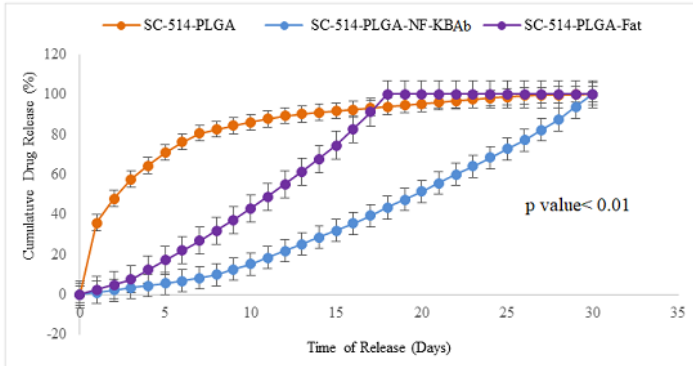

Figure 2: The SC-514 released from three different encapsulations (SC-514-PLGA, SC-514-PLGA-NF-KBAb, and SC-514-PLGA-Fat) was investigated over 30 days. SC-514 released from SC-514-PLGA encapsulations indicated a first order release curve with initial outburst. SC-514-PLGA-NF-KBAb indicated a first order release curve from day 1 to day 30. SC-514-PLGA-Fat displayed increasing cumulative release of SC-514 up until day 18 , from day 18 to day 30

the cumulative release was the same for SC-514-PLGA-Fat formulation

\begin{tabular}{|c|c|c|}
\hline Days & $\begin{array}{c}\text { Number of } \\
\text { colonies of PC-3 } \\
\text { cells after release } \\
\text { of SC-514 }\end{array}$ & $\begin{array}{c}\text { Cumulative number of } \\
\text { colonies of PC-3 cells } \\
\text { formed after release of } \\
\text { SC-514 drug }\end{array}$ \\
\hline 0 & 0 & 0 \\
\hline 1 & 30 & 30 \\
\hline 2 & 69 & 99 \\
\hline 3 & 65 & 164 \\
\hline 4 & 54 & 218 \\
\hline 5 & 49 & 267 \\
\hline 6 & 34 & 301 \\
\hline 7 & 32 & 333 \\
\hline 8 & 27 & 360 \\
\hline 9 & 25 & 385 \\
\hline 10 & 25 & 410 \\
\hline 11 & 24 & 434 \\
\hline 12 & 24 & 458 \\
\hline 13 & 23 & 481 \\
\hline 14 & 21 & 502 \\
\hline-15 & 20 & 522 \\
\hline 16 & 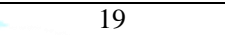 & 541 \\
\hline 17 & 18 & 559 \\
\hline 18 & 17 & 576 \\
\hline 19 & 16 & 592 \\
\hline 20 & 15 & 607 \\
\hline 21 & 14 & 621 \\
\hline 22 & 13 & 634 \\
\hline 23 & 12 & 646 \\
\hline 24 & 11 & 657 \\
\hline 25 & 10 & 667 \\
\hline 26 & 9 & 676 \\
\hline 27 & 9 & 685 \\
\hline 28 & 9 & 694 \\
\hline 29 & 9 & 703 \\
\hline 30 & 9 & 712 \\
\hline
\end{tabular}

Table 4: PC-3 cells colonies counted for colony assay.

\section{Alternative methods for quantifying SC-514 drug released from SC-514 PLGA}

The results from colony forming assay are shown in Figure $\mathbf{5}$ and Table 4. The number of days of drug release study and cumulative number of colonies of PC-3 cells formed after release of SC-514 drug from SC-514-PLGA nanoparticles was plotted to produce a drug release curve (Figure 3).

The results from the transwell migration and invasion assay, shown in table 5 below are indicated in the stained form (Figures 5, 6, and 7) and unstained form (Figure 8). The number of days of drug release study and number of PC-3 cells in the lower chamber of transwell after release of SC-514 drug from SC-514-PLGA nanoparticles was plotted to produce a drug release curve (Figure 3). As drug release progressed from day 0 to day 30 , number of PC3 cells in the lower chamber of transwell after release of SC-514 drug from SC-514-PLGA decreased. However, as drug release progressed, cumulative number of PC-3 cells in the lower chamber of transwell also increased.

The results from the wound healing assay are indicated on day 1 to day 6 (Figure 9 and Table 6). The number of days of drug release study and cumulative width over time after release of SC-514 drug from SC-514-PLGA nanoparticles was plotted to produce a drug release curve (Figure 3 ). As the drug release progressed from day 1 to day 30 , the wound width created decreased from day 1 to day 30 . However, the cumulative wound width increased. Drug release curve was constructed for the purpose of comparing different SC514 quantification methods (Figure 3). 


\begin{tabular}{|c|c|c|}
\hline Days & $\begin{array}{c}\text { Number of PC-3 } \\
\text { cells in the lower } \\
\text { chamber of transwell } \\
\text { after release of SC- } \\
514 \text { drug from SC- } \\
\text { 514-PLGA }\end{array}$ & $\begin{array}{l}\text { Cumulative number of } \\
\text { PC-3 cells in the lower } \\
\text { chamber of transwell } \\
\text { after release of SC-514 } \\
\text { drug from SC-514-PLGA }\end{array}$ \\
\hline 0 & 0 & 0 \\
\hline 1 & 620 & 620 \\
\hline 2 & 1670 & 2290 \\
\hline 3 & 1540 & 3830 \\
\hline 4 & 1304 & 5134 \\
\hline 5 & 1234 & 6368 \\
\hline 6 & 1005 & 7373 \\
\hline 7 & 856 & 8229 \\
\hline 8 & 654 & 8883 \\
\hline 9 & 640 & 9523 \\
\hline 10 & 550 & 10073 \\
\hline 12 & 530 & 10603 \\
\hline 13 & 528 & 11131 \\
\hline 14 & 526 & 11657 \\
\hline 15 & 523 & 12180 \\
\hline 16 & 520 & 12700 \\
\hline 17 & 517 & 13217 \\
\hline 18 & 515 & 13732 \\
\hline 19 & 513 & 14245 \\
\hline 20 & 509 & 14754 \\
\hline 21 & 505 & 15259 \\
\hline 22 & 504 & 15763 \\
\hline 23 & 501 & 16264 \\
\hline 24 & 498 & 16762 \\
\hline 25 & 496 & 17258 \\
\hline 26 & 493 & 17751 \\
\hline 27 & 492 & 18243 \\
\hline 28 & 492 & 18735 \\
\hline 29 & 491 & 19226 \\
\hline 30 & 491 & 19717 \\
\hline
\end{tabular}

Table 5: PC-3 cells counted for transwell migration and invasion assay.

\section{Alternative methods for SC-514 Drug Release Studies}

Transwell assay staining of LNCaP cells, PC-3 cells, and DU-145 cells that indicated a more consistent trend of drug release pattern was observed in PC-3 cells than in LNCaP cells and DU-145 cells (Figure 5 and Figure 6).

The colonies formed from $\mathrm{LNCaP}$ cells were the most sensitive to SC-514 drug release, followed by the colonies formed from DU-145 cells. The colonies formed by PC-3 cells were the least sensitive to SC-514 drug release. This trend is in consistency with aggressiveness of the prostate cancer cell lines utilized (PC-3 cells are the most aggressive during proliferation and $\mathrm{LNCaP}$ cells are the least aggressive). The higher the aggressiveness of the prostate cancer lines, the lower the sensitivity of the colony cells formed to the SC-514 drug release.

Transwell assay staining of PC-3 cells suggested that more SC-514 was released from SC-514-PLGA nanoparticles (cumulative release) as the days progressed from day 1 to day 12 , which correlated with the reduction in number of PC-3 cells that migrated through the filter from day 1 to day 12 .

\begin{tabular}{|c|c|c|}
\hline Days & $\begin{array}{c}\text { Wound } \\
\text { width over } \\
\text { time }\end{array}$ & $\begin{array}{c}\text { Cumulative width } \\
\text { over time }\end{array}$ \\
\hline 0 & 78 & 78 \\
\hline 1 & 69 & 147 \\
\hline 2 & 67 & 214 \\
\hline 3 & 64 & 278 \\
\hline 4 & 61 & 339 \\
\hline 5 & 58 & 397 \\
\hline 6 & 55 & 452 \\
\hline 7 & 53 & 505 \\
\hline 8 & 50 & 555 \\
\hline 9 & 47 & 602 \\
\hline 10 & 45 & 647 \\
\hline 11 & 43 & 690 \\
\hline 12 & 41 & 731 \\
\hline 13 & 37 & 768 \\
\hline 14 & 34 & 802 \\
\hline 15 & 31 & 833 \\
\hline 16 & 27 & 860 \\
\hline 17 & 24 & 884 \\
\hline 18 & 20 & 904 \\
\hline 19 & 18 & 922 \\
\hline 20 & 15 & 937 \\
\hline 21 & 12 & 949 \\
\hline 22 & 11 & 960 \\
\hline 23 & 10 & 970 \\
\hline 24 & 9 & 979 \\
\hline 25 & 8 & 987 \\
\hline 26 & 7 & 994 \\
\hline 27 & 6 & 1000 \\
\hline 28 & 5 & 1005 \\
\hline 29 & 5 & 1010 \\
\hline 30 & 5 & 1015 \\
\hline
\end{tabular}

Table 6: Wound width between monolayer of PC-3 cells forming the wound in the wound assay.

\section{Methods for quantifying SC-514 Drug Released from} SC-514 PLGA Nanoparticles

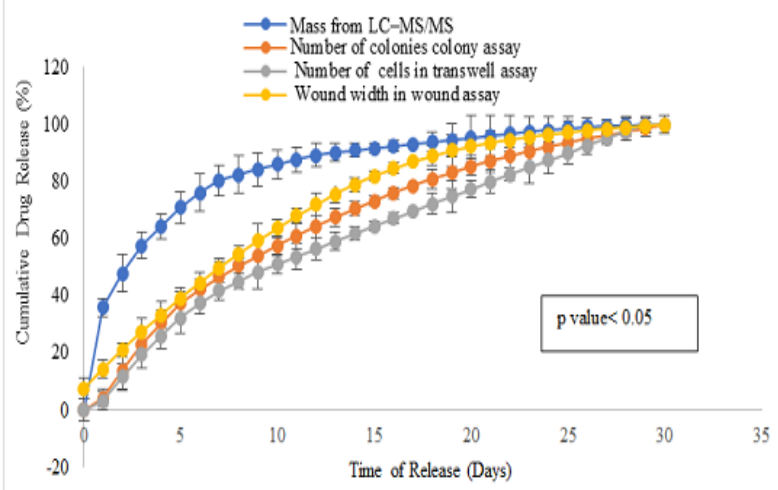

Figure 3: Four methods were utilized to investigate the release of SC-514 drug from SC-514-PLGA nanoparticle over 30 days. Three of these methods were new and unconventional (Colony assay, transwell assay, and wound assay). Colony assay, transwell assay, and wound assay methods indicated a similar trend of drug release with no outburst release of the SC-514 drug. LC-MS/MS conventional method indicated that SC-514 released from SC-514

PLGA encapsulations is a first order release curve with initial outburst. 

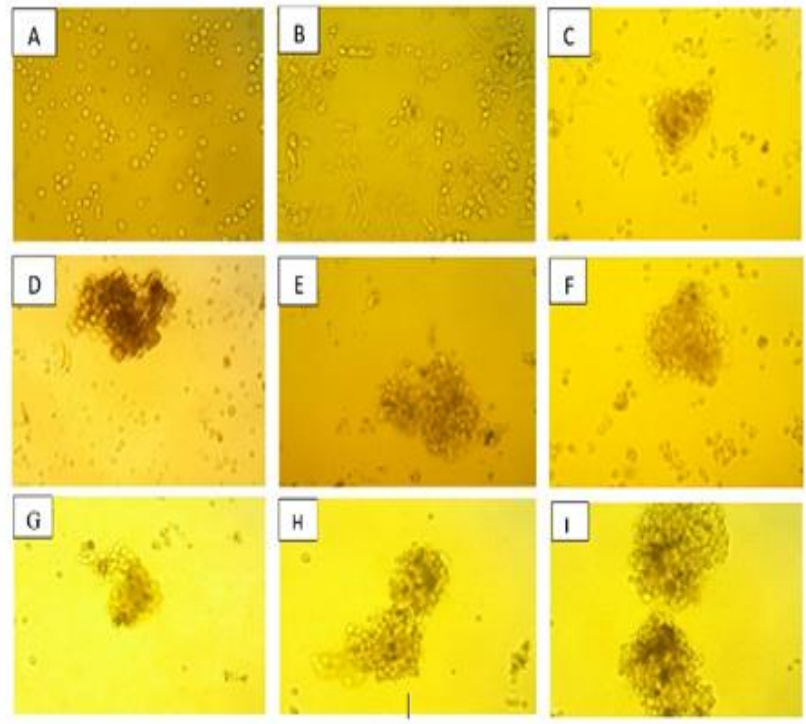

Figure 4: The result from colony forming assay of PC-3 cells as an alternative method to quantify $\mathrm{SC}-514$ drug release. A: $0 \mathrm{~h}$ of cell culture, B: $48 \mathrm{~h}$ of control, C: release of SC-514 from SC-514PLGA on day 1, D: release of SC-514 from SC-514-PLGA on day 2, E: release of SC-514 from SC-514-PLGA on day 3, F: release of SC-514 from SC-514-PLGA on day 4, G: release of SC-514 from SC-514-PLGA on day 5, H: release of SC-514 from SC-514-PLGA on day 6, I: release of SC-514 from SC-514-PLGA on day 7.
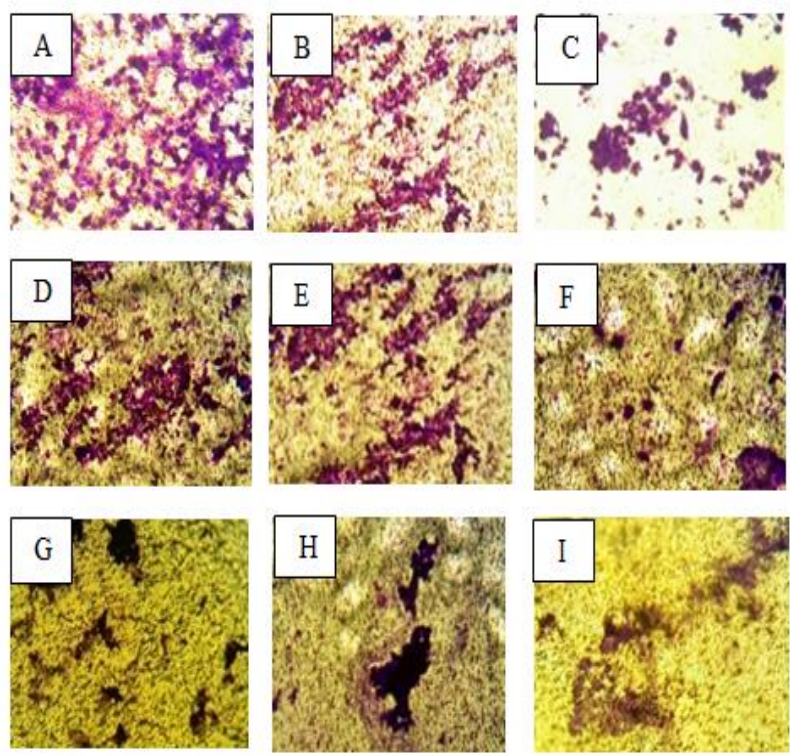

Figure 5: The result from colony forming assay of $\mathrm{LNCaP}$ cells, PC-3 cells, and DU-145 cells as an alternative method for SC-514 drug release study. The experiment was carried out in the same transwell under the same condition of cell culture: A: release of SC514 from SC-514-PLGA on day 1 to LNCaP cells, B: release of SC514 from SC-514-PLGA on day 2 to LNCaP cells, C: release of SC514 from SC-514-PLGA on day 3 to LNCaP cells, D: release of SC514 from SC-514-PLGA on day 1 to DU-145 cells, E: release of SC-514 from SC-514-PLGA on day 2 to DU-145 cells, F: release of SC-514 from SC-514-PLGA on day 3 to DU-145 cells, G: release of SC-514 from SC-514-PLGA on day 1 to PC-3 cells, H: release of

SC-514 from SC-514-PLGA on day 2 to PC-3 cells, I: release of SC-514 from SC-514-PLGA on day 3 to PC-3 cells.
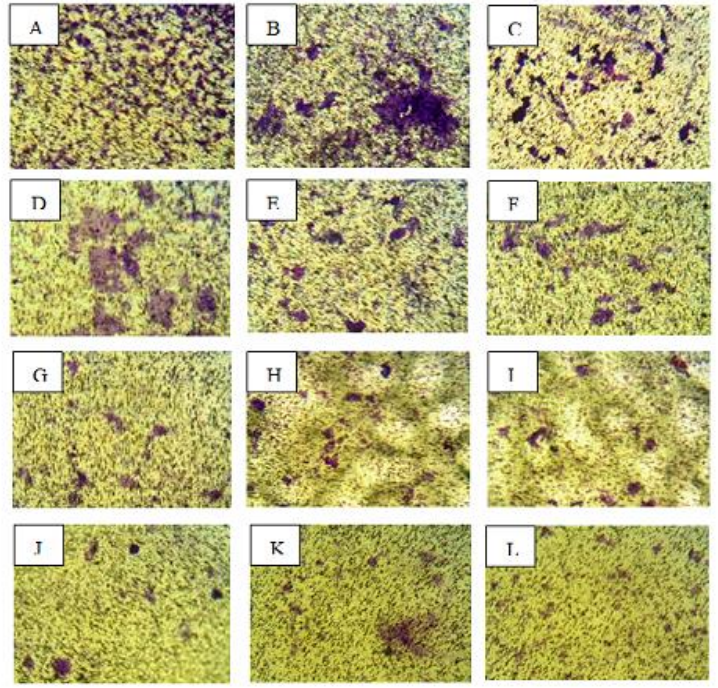

Figure 6: Transwell assay showing the number of PC-3 cells that migrated through the transwell after release of SC-514 drug from SC-514-PLGA. A: release of SC-514 drug from SC-514-PLGA on day 1, B: release of SC-514 drug from SC-514-PLGA on day 2, C: release of SC-514 drug from SC-514-PLGA on day 3, D: release of SC-514 drug from SC-514-PLGA on day 4, E: release of SC-514 drug from SC-514-PLGA on day 5, F: release of SC-514 drug from SC-514-PLGA on day 6, G: release of SC-514 drug from SC-514PLGA on day 7, H: release of SC-514 drug from SC-514-PLGA on day 8, I: release of SC-514 drug from SC-514-PLGA on day 9, J: release of SC-514 drug from SC-514-PLGA on day 10, K: release of SC-514 drug from SC-514-PLGA on day11, L: release of SC-514 drug from SC-514-PLGA on day 12.

Transwell assay showing the number of DU-145 cells that migrated through the transwell after the release of SC-514 drug to the DU145 cells from SC-514-PLGA nanoparticles.
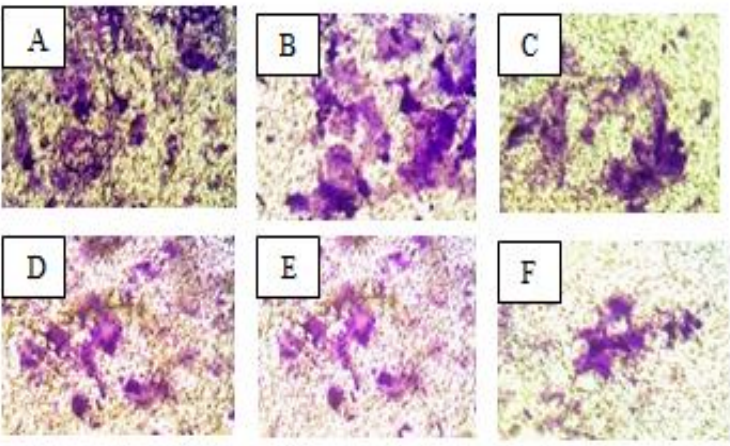

Figure 7: Transwell assay showing the number of DU-145 cells that migrated through the transwell after release of SC-514 drug from SC-514-PLGA. A: release of SC-514 drug from SC-514-PLGA on day 1, B: release of SC-514 drug from SC-514-PLGA on day 2, C: release of SC-514 drug from SC-514-PLGA on day 3, D: release of SC-514 drug from SC-514-PLGA on day 4, E: release of SC-514 drug from SC-514-PLGA on day 5, F: release of SC-514 drug from SC-514-PLGA on day 6.

Transwell assay showing the number of unstained PC-3 cells that migrated through the transwell after release of SC-514 drug from SC-514-PLGA on the PC-3 prostate cancer cells from day 1 to day 30 .

Citation: Famuyiwa TO, Bowers Z, Bentley A, Caraballo D, Subtil P, et al. Drug release studies of SC-514 PLGA nanoparticles (2021) Pharmacovigil and Pharmacoepi 4: 1-21. 

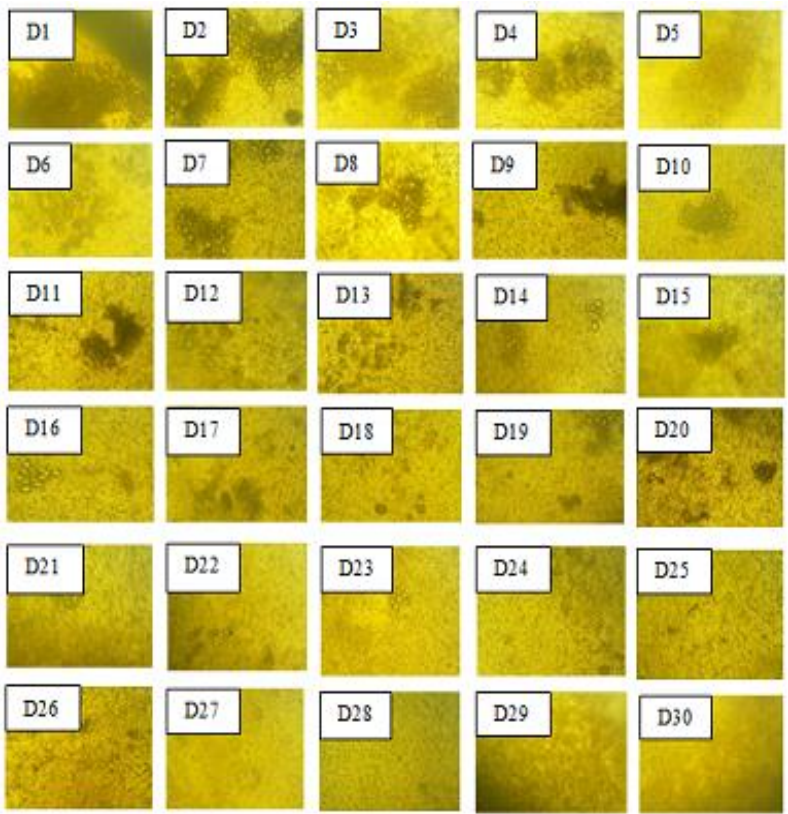

D30

Figure 8: Transwell assay showing the number of unstained PC-3 cells that migrated through the transwell after release of SC-514 drug from SC-514-PLGA from day 1 to day 30. D1: release of SC514 drug from SC-514-PLGA on day1, D2: release of SC-514 drug from SC-514-PLGA on day 2, D3: release of SC-514 drug from SC514-PLGA on day 3, D4: release of SC-514 drug from SC-514-

PLGA on day 4, D5: release of SC-514 drug from SC-514-PLGA on day 5, D6: release of SC-514 drug from SC-514-PLGA on day 6,

D7: release of SC-514 drug from SC-514-PLGA on day 7, D8: release of SC-514 drug from SC-514-PLGA on day 8, D9: release of SC-514 drug from SC-514-PLGA on day 9, D10: release of SC-514 drug from SC-514-PLGA on day 10, D11: release of SC-514 drug from SC-514-PLGA on day 11, D12: release of SC-514 drug from SC-514-PLGA on day 12, D13: release of SC-514 drug from SC514-PLGA on day 13, D14: release of SC-514 drug from SC-514PLGA on day 14, D15: release of SC-514 drug from SC-514-PLGA on day 15, D16: release of SC-514 drug from SC-514-PLGA on day 16, D17: release of SC-514 drug from SC-514-PLGA on day 17, D18: release of SC-514 drug from SC-514-PLGA on day 18, D19: release of SC-514 drug from SC-514-PLGA on day 19, D20: release of SC-514 drug from SC-514-PLGA on day 20, D21: release of SC514 drug from SC-514-PLGA on day 21, D22: release of SC-514 drug from SC-514-PLGA on day 22, D23: release of SC-514 drug from SC-514-PLGA on day 23, D24: release of SC-514 drug from SC-514-PLGA on day 24, D25: release of SC-514 drug from SC514-PLGA on day 25, D26: release of SC-514 drug from SC-514PLGA on day 26, D27: release of SC-514 drug from SC-514-PLGA on day 27, D28: release of SC-514 drug from SC-514-PLGA on day 28, D29: release of SC-514 drug from SC-514-PLGA on day 29,

D30: release of SC-514 drug from SC-514-PLGA on day 30.

Wound healing assay of unstained PC-3 cells was conducted as an alternative method for drug release study. On day 6 of drug release (Figure 9H), there were less fibroblastic PC-3 cells compared to the day 6 control with no release of SC-514 drug from SC-514-PLGA (Figure 9I). Also, the $\mathrm{PC}-3$ cells in the wells that received cumulative release of SC-514 drug were rounded up, clumped together and not well attached to the surface of the culture plate by day 6 (Figure 9H). On the other hand, the PC-3 cells with no release of SC-514 drug from SC-514-PLGA (control) on day 6 appeared elongated, spaced out at good distance and well-attached the surface of the wells (Figure 9I).
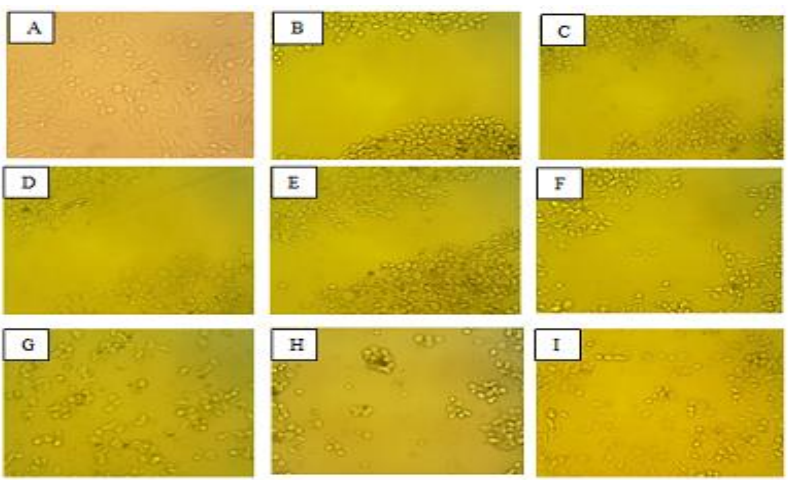

Figure 9. Wound healing assay of unstained PC-3 cells as an alternative method for drug release study. A: $48 \mathrm{~h}$ (day 2) control with no release of SC-514 drug from SC-514-PLGA, B: release of SC-514 drug from SC-514-PLGA on day 0, C: release of SC-514 drug from SC-514-PLGA on day 1, D: release of SC-514 drug from SC-514-PLGA on day 2, E: release of SC-514 drug from SC-514PLGA on day 3, F: release of SC-514 drug from SC-514-PLGA on day 4, G: release of SC-514 drug from SC-514-PLGA on day 5, H: release of SC-514 drug from SC-514-PLGA on day 6, I: day 6 control with no release of SC-514 drug from SC-514-PLGA.

The intracellular delivery of SC-514 from poly (lactide-coglycolide) (PLGA) nanoparticles stabilized with bovine serum albumin, in PC-3 cells, was studied via confocal microscopy (Nikon A1R Confocal System w/SIM). As the incubation time changes, florescence intensity and cellular uptake changes (Figure 11).

The cellular uptake efficiency of nanoparticles in PC-3 prostate cancer cell was higher in the SC-514-PLGA-NF-KBAb NPs than SC-514-PLGA NPs (Figure 13). This is consistent with the results of the drug release study (Figure 2) and the impact of SC-514 nanoparticle formulations on PC-3 cells (Figure 19 and 20) and cord blood cells (Figure 17 and figure 18). It takes a longer time for SC-514-PLGA-NF-KBAb to release the SC-514 drug content because of the high cellular uptake efficiency of the whole nanoparticles in cells. On the other hand, SC-514-PLGA NPs has lower cellular uptake efficiency with a burst release at the beginning of the drug release study.

The degree of enhanced cellular accumulation of PLGA-SC-514 NPs was higher in prostate cancer cells than cord blood cells (Figure 12). The underlying mechanisms of enhanced cellular accumulation efficiency of SC-514-PLGA NPs compared with that of PLGA NPs should be further investigated. Generally, there was an increased concentration of nanoparticles in PC-3 cells because of increased incubation time.
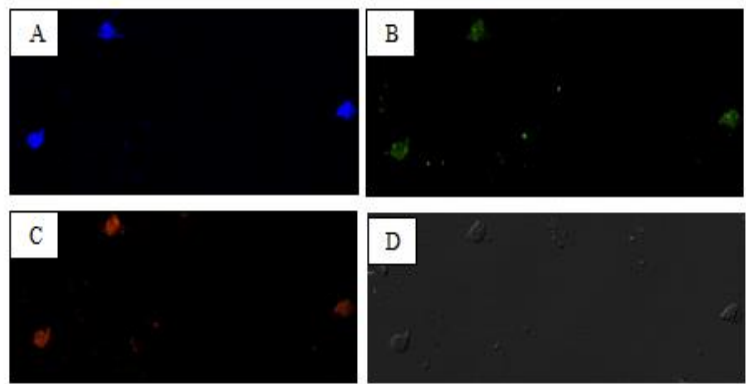

Figure 10: Picture showing PC-3 cells and SC-514-PLGA nanoparticles. A: Nucleus stain of PC-3 cells with DAPI B: Expression of multidrug resistance in PC-3 cells, C: SC-514-PLGA nanoparticles in PC-3 cells, D: Phase contrast image of PC- 3 cells. These images represent $\mathrm{x}-\mathrm{y}$ confocal images (20x magnification). 

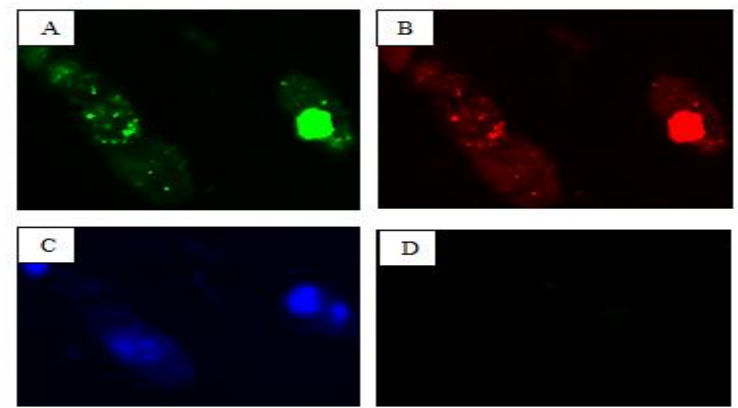

Figure 11: Confocal microscopy of PC-3 prostate cancer cells following uptake of PLGA nanoparticles. Confocal microscopy demonstrated that nanoparticles were internalized rapidly, with nanoparticles seen inside the cells as early as within 15 min after incubation. The nanoparticle uptake increased with incubation time in the presence of nanoparticles in the culture medium. Intensity of color observed was utilized to determine the extent of nanoparticles uptake. These images represent $x-y$ confocal images $(60 x$ magnifications). A: Green indicated the expression of nanoparticles inside PC-3 cells after incubation for $30 \mathrm{~min}$ at $37^{\circ} \mathrm{C}$. B: Red indicated the expression of nanoparticles inside the PC-3 cells after incubation for $15 \mathrm{~min}$ at $37{ }^{\circ} \mathrm{C}$. C: Blue indicates the nucleus of the PC-3 cells. Nucleic was stained with DAPI. D: PC-3 cells were incubated with PBS only (0.01 M, pH 7.4).

The degree of cellular accumulation of PLGA-SC-514 NPs was higher in prostate cancer cells than cord blood cells (Figure 12). The effect of the nanoparticle treatment on PC-3 cells was also investigated (Figure 14). This study utilized immunofluorescence assay to investigate the expressing of MDR proteins after treatment with free SC-514 and SC-514-PLGA nanoparticles. SC-514-PLGA nanoparticles reduced the expression of MDR protein in $\mathrm{PC}-3$ cells significantly more than free SC-514. Controlled and optimum delivery of SC-514 drug from the nanoparticle treatment PLGA NPs has the potential to eliminate the imbalance in the length of drug treatment favoring MDR in prostate cancer. This will potentially reduce the expression of $\mathrm{P}$-gp and other $\mathrm{ABC}$ transporter proteins in prostate cancer during treatment. Reduction in cell viability was observed when PC-3 cells were incubated with the nanoparticle formulations for $48 \mathrm{~h}$ at $37^{\circ} \mathrm{C}$ and $5 \% \mathrm{CO}_{2}$. Varying concentrations of SC-514 released from the nanoparticle formulation inhibited the cell growth. The growth inhibition was manifested by shrinking and granulation of PC-3 prostate cancer cells (Figure 15).
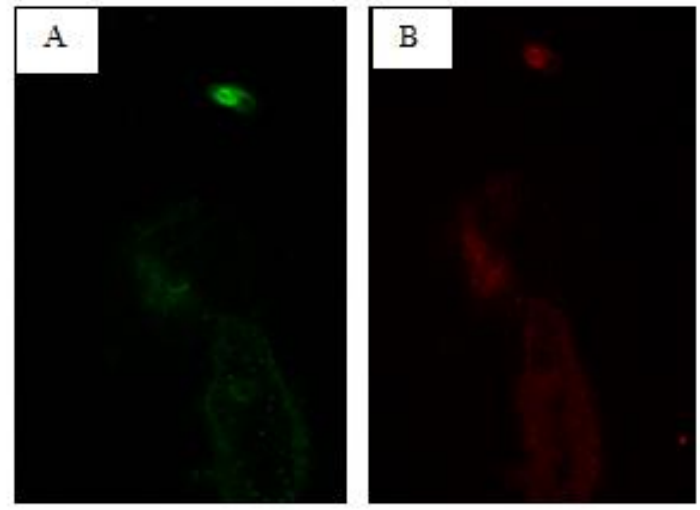

Figure 12: The degree of cellular accumulation of PLGA-SC-514 NPs was higher in prostate cancer cells than cord blood cells. The result is based on the intensity of color at any point in time. A: The Green fluorescence indicated cellular accumulation of PLGA-SC514 NPs in PC-3 cells, B: The red fluorescence indicated cellular accumulation of PLGA-SC-514 NPs in cord blood cells.
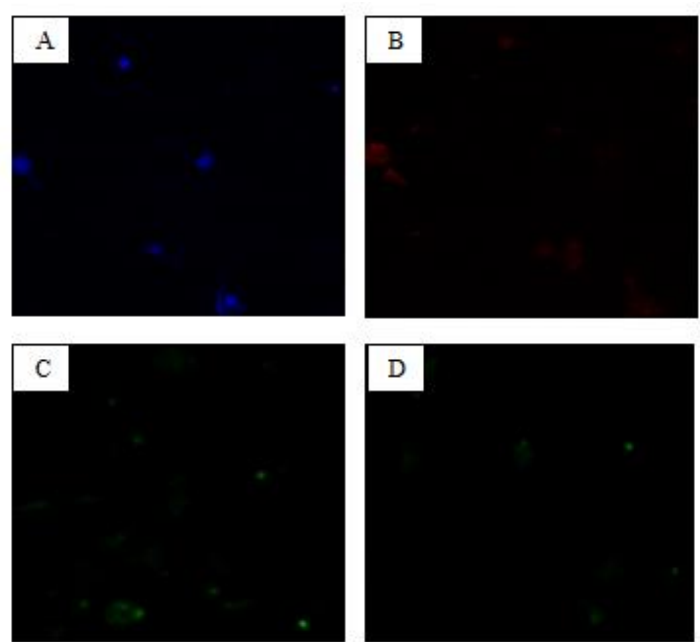

Figure 13: Quantitative study of PLGA nanoparticles uptake in PC3 cells. A: nucleus of PC-3 cells stained blue with DAPI (4',6diamidino-2- phenylindole), B: NF-KBab expression in PC-3 cells without nanoparticles. C: SC-514-PLGA-NF-KB nanoparticle in PC-3 cells, D:SC-514-PLGA nanoparticle in PC-3 cells.
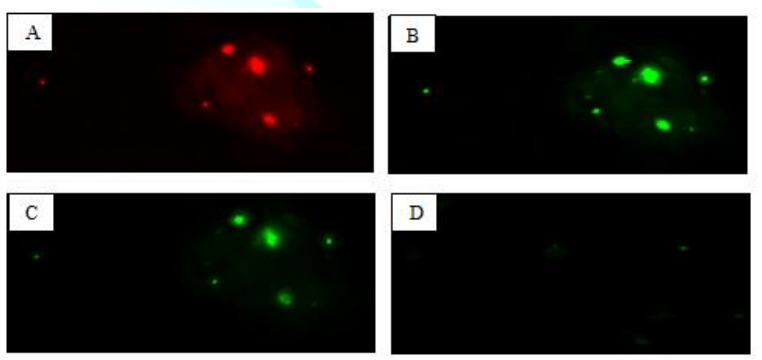

Figure 14: Expression of MDR in PC-3 prostate cancer cells. A: SC-PLGA nanoparticles, B: Bright green color with high expression of MDR from PC-3 cells treated with Free SC-514 C: Lower expression of MDR from PC-3 cells treated with SC-514-PLGA nanoparticles D: Control containg no PC-3 cells but has MDR stain indicatecd little or no expression of MDR.

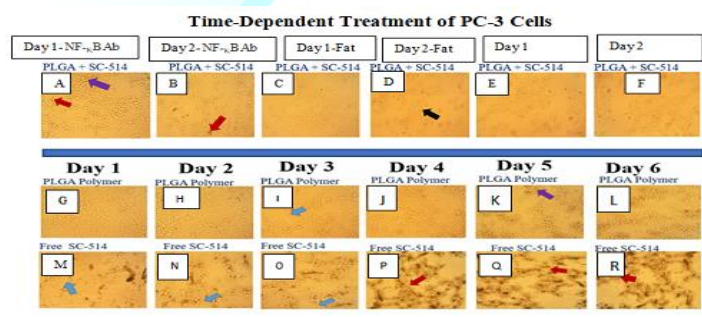

Figure 15: The appearance and structural characteristics of $\mathrm{PC}-3$ prostate cancer cells after treatment with PLGA polymer, free SC514, SC-514-PLGA- NF-KBAb, SC-514-PLGA- Fat, and SC-514PLGA. A: Day 1 treatment of PC-3 prostate cancer cells with SC514-PLGA- NF-KB at $4.86 \mu \mathrm{M}$ concentration of SC-514, B: Day 2 treatment of PC-3 prostate cancer cells with SC-514-PLGA-NF-KB at $9.72 \mu \mathrm{M}$ concentration of SC-514, C: Day 1 treatment of PC-3 cells with SC-514-PLGA- Fat at $4.59 \mu \mathrm{M}$ concentration of SC-514, D: Day 2 treatment of PC-3 cells with SC-514-PLGA- Fat at 5.04 $\mu \mathrm{M}$ concentration of SC-514, E: Day 1 treatment of PC-3 cells with SC-514-PLGA at concentration $71.78 \mu \mathrm{M}$ of SC-514, F: Day 2 treatment of PC-3 cells with SC-514-PLGA at concentration 23.94 $\mu \mathrm{M}$ of SC-514. G-L: Day 1 to Day 6 treatment of PC-3 cells with PLGA polymer only respectively. M-R: Day 1 to Day 6 treatment of PC-3 cells with free SC-514 respectively. 


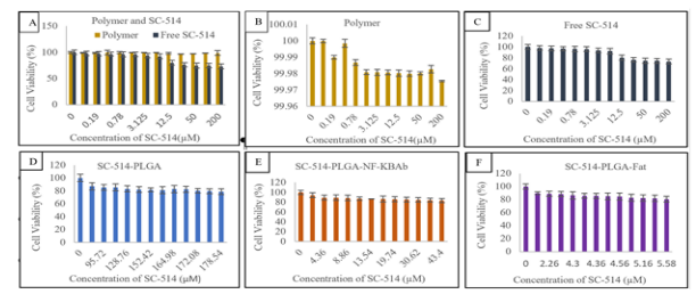

Figure 16: Cord blood cells treatment with SC-514 drug release from nanoparticle treatments at different concentrations impacting different levels of cell viabilities. A:comparison between cell viabilities of cord blood cells treated with polymer and free SC-514, B: cell viability of cord blood cells treated with polymer, C: cell viability of cord blood cells treated with free SC-514, D: cell viability of cord blood cells treated with SC-514-PLGA, E: cell viability of cord blood cells treated with SC-514-PLGA- NF-KBAb, F: cell viability of cord blood cells treated with SC-514-PLGA-Fat.

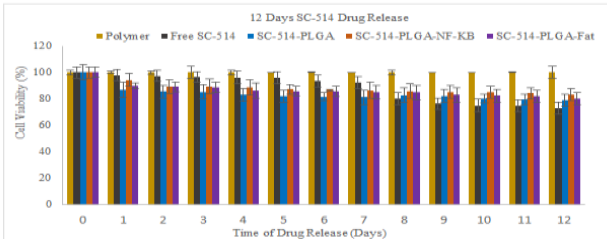

Figure 17: Cord blood cells treatment with SC-514 drug release from nanoparticle treatments impacted different levels of cell viability from day 1 to day 12. Concentrations of polymer and free SC-514 from day 1 to day 12 ranged from $0 \mu \mathrm{M}$ to $200 \mu \mathrm{M}$. Concentrations of the other nanoparticle treatments (SC-514-PLGA, SC-514-PLGA-NF- ${ }_{\mathrm{K}} \mathrm{BAb}$, SC-514-PLGA-Fat) administered was based on drug release from day 1 to day 12 as reported earlier.
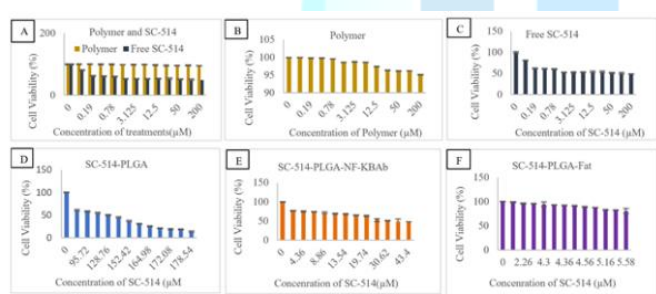

Figure 18: PC-3 cells treatment with SC-514 drug release from nanoparticle treatments at different concentrations impacted different levels of cell viabilities. A: comparison between cell viability of PC-3 cells treated with polymer and free SC-514, B: cell viability of PC-3 cells treated with polymer, C:cell viability of PC-3 cells treated with free SC-514, D: cell viability of PC-3 cells treated with SC-514-PLGA, E: cell viability of PC-3 treated with SC-514PLGA-NF-KBAb, F: cell viability of PC-3 cells treated with SC514-PLGA-Fat.

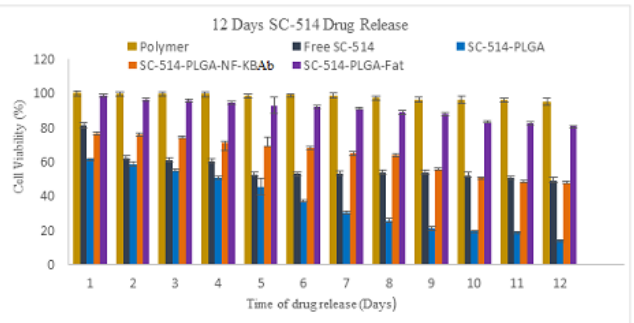

Figure 19: The cell viability of PC-3 cells after treatment with SC514 drug concentrations obtained from the in-vitro drug release profile of the nanoparticle treatments measured in a bio-relevant medium from day 1 to day 12 . Concentrations of polymer and free SC-514 from day 1 to day 12 ranged from $0 \mu \mathrm{M}$ to $200 \mu \mathrm{M}$.

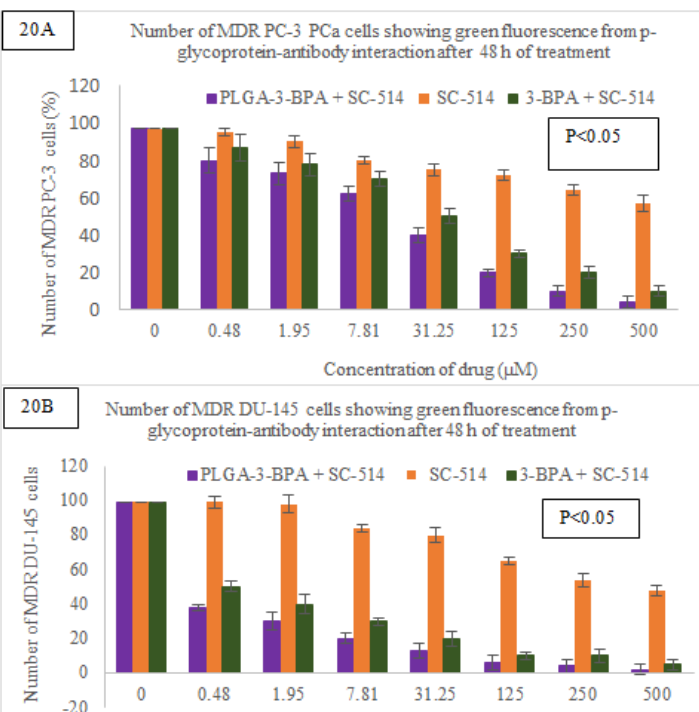

Figure 20: Immunofluorescence analysis results detecting $\mathrm{p}-$ glycoprotein-antibody interaction and cell tracker tagged to 3-BPA and/or SC-514. The green fluorescence from p-glycoproteinantibody interaction estimated the number of MDR PC-3 PCa cells and MDR DU-145 cells after treatment. Figure 20A shows the number of MDR PC-3 cells observed after $48 \mathrm{~h}$ treatment with PLGA-3-BPA + SC-514, SC-514, and 3-BPA+SC-514. Data represented are the mean of \pm SEM of three independent experiments. Figure 20B: Immunofluorescence analysis results detecting p-glycoprotein-antibody interaction and cell tracker tagged to PLGA-3-BPA + SC-514, SC-514, and 3-BPA +SC-514. The

green fluorescence from p-glycoprotein-antibody interaction estimated the number of MDR DU-145 PCa cells after treatment. This figure shows the number of MDR DU-145 cells observed after $48 \mathrm{~h}$ treatment with PLGA-3-BPA + SC-514, SC-514, and 3-BPA

$+\mathrm{SC}-514$. Data represented are the mean of \pm SEM of three independent experiments.

\section{Result and Discussion}

The conventional cancer chemotherapy has many negative effects such as Multiple Drug Resistance (MDR), high clearance rate (pharmacokinetic measurement of the volume of plasma from which a drug is completely removed per unit time), severe side effects, unwanted drug distribution to the normal cells and low concentration of drug at the site of prostate cancer cells [111]. Therefore, it is necessary to develop novel strategies and novel Nano carriers that will carry the drug molecules directly to the affected cancerous cells in an adequate amount and duration within effective therapeutic window [112,113]. Nanoparticle drug delivery systems have advantages over conventional chemotherapy due to the high efficacy of drug loading or drug encapsulation efficiency, high cellular uptake, high drug release, and minimum side effects. These Nano carriers possess high drug accumulation in the tumor area while minimizing toxic effects on healthy prostate tissues [112].

To reduce MDR in prostate cancer treatment, this study investigated the therapeutic advantage of encapsulating SC-514 in PLGA polymer and conjugating the surface of the nanoparticles formed to further control drug delivery. The water-insoluble SC-514 drug in a hydrophobic PLGA based matrix showed average drug loading due to leaching effects (uncontrolled accidental release of drug). Therefore, SC-514-PLGA nanoparticles were conjugated with NFKB antibody and Fats. It was necessary to develop a useful method to increase the drug encapsulation efficiency and improve the drug bioavailability of SC-514. 
Further improvement of SC-514 drug entrapment by conjugation during nanoparticle formulation can be considered advantageous in reduction of multidrug resistance in prostate cancer. This is important because prolonged drug release has been shown to reduce drug resistance in cancer treatment $[114,115]$. The goal of this study was to investigate SC-514 drug release from nanoparticle formulations that has the potential to reduce multidrug resistance by sustained release of SC-514 drug from the PLGA nanoparticle formulations.

The use of Nano encapsulation of SC-514 will improve the chance to target the prostate cancer cells and not harm normal prostate cells because targeted drug delivery of nanoparticles decorated with sitespecific recognition ligands is of considerable interest to minimize cytotoxicity of chemotherapeutics in the normal cells [115]. SC-514 was internalized into the PLGA nanoparticles by endocytosis which may be released via endosome escape delivering the encapsulated SC-514 drug to the cytosol of the cells. Higher intracellular delivery of the SC-514 drug from the nanoparticles suggested a high efficacy of encapsulated SC-514 drug. Hence, lower dose of the SC-514 nanoparticle formulation could produce a higher cytotoxic effect on the cancer cells than free SC-514 drug (Figure 16 and Figure 18). Previously, SC-514-loaded poly (lactic-co-glycolic acid) (PLGA) nanoparticles (SC-514-PLGA) were prepared by the single emulsion method. The influence of different experimental parameters on the incorporation of SC-514 in the nanoparticles was evaluated. Functionalized SC-514 PLGA nanoparticles were prepared based on previously modified method [46]. We utilized various techniques for drug solubility enhancement including nanoparticle surface functionalization. The surface of SC-514-PLGA polymeric drug delivery system was functionalized with NF-KB antibody and fat to form SC-514-PLGA-NF-KBAb and SC-514-PLGA-Fat respectively. The functionalization was done to further improve the therapeutic index of SC-514 drug and reduce the adverse treatment effects in this current study. This impact of of functionalization in this current study is similar the results from other studies [116,117].

Delivering chemotherapeutics by nanoparticles into a tumor is mostly impeded by two factors: nonspecific targeting and inefficient penetration. Targeted delivery of anti-cancer agents solely to tumor cells introduces a smart strategy because it enhances the therapeutic index compared to untargeted mode of delivery of drugs [118]. The anti-cancer effect of SC-514 nanoparticle formulations (SC-514PLGA, SC-514-PLGA-NF-KBAb, and SC-514-PLGA-Fat nanoparticles) on cord blood cells and PC-3 cells was investigated.

The release behavior of SC-514 from the developed SC-514-PLGA exhibited a biphasic pattern characterized by an initial fast release during the first 24 hours, followed by a slower and continuous release (Figure 2). This is very similar to the burst release observed in other studies [119-121], thus, confirming the treatment efficacy of the nanoparticle delivery approach. Drug release from SC-514PLGA nanoparticles appears to consist of two components with an initial rapid release followed by a slower exponential stage (Figure 2). SC-514-PLGA nanoparticles indicated that $50 \%$ of the drug was released on the 3rd day. The SC-514-PLGA-NF-KBAb indicated that $50 \%$ of the drug was released on the 20th day. SC-514-PLGAFat indicated that $50 \%$ of the drug was released on the 12th day. For all the nanoparticle formulations, $50 \%$ of drug release extended from hours to weeks in this current study.

A model predicts a two-stage release profile, with a relatively rapid initial release of most of the drug, followed by a slower release of the remaining drug known as a "plateau" phase [122]. This is consistent with the results from SC-514-PLGA drug release in this study (Figure 2). Faster initial release of SC-514 in SC-514-PLGA than in SC-514-PLGA-NF-KBAb and SC-514-PLGA-Fat might be due to a faster dissociation of polylactic acid-glycolic acid polymer.
Generally, low-MW drugs, peptides, and proteins have higher propensities for burst release as a result of osmotic pressures [123].

In most treatments, a strong burst release is to be avoided as it decreases the efficacy of the treatment and can be dangerous to the host [120]. It may also waste the SC-514 drug if the excess drug cannot be absorbed by the body within the time of administration. Although under certain circumstances an initial sharp release of the therapeutic agent could be desirable, it is often unpredictable with uncontrollable duration and dose $[8,123]$. For example, if a sudden voluminous delivery is required, burst release can be triggered by rapid changes in the local environment. However, for the most part, avoiding the burst release effect is desirable to minimize any initial toxicity associated with a high dose. For this reason, various methods have been recommended to control unnecessary and dangerous burst release of drugs [123] as seen with the SC-514PLGA nanoparticles drug release in this current study. To maximize the effectiveness of nanoparticle targeting, drug release from nanoparticles needs to be slow enough to avoid substantial drug loss before the carrier reaches the site of action thereby reducing toxicity [124,125]. Initial burst can be further controlled by modifying the solidification rate of the dispersed phase [126]. In order to prevent many unfavorable events such as pore formation, drug loss, and drug migration that occurred while the dispersed phase is in the semi-solid state, it is important to understand and optimize the nanoparticle formulation variables [127]. In this study, we functionalized the surface of PLGA nanoparticles with molecules including NF-KB antibody and fat to remove the burst release problem observed previously.

SC-514-PLGA was conjugated with NF-KB antibody in order to investigate the impact of NF-KB antibody rich microenvironment on SC-514 drug release. Elevated expression of NF-KB has been implicated in prostate cancer carcinogenesis [128]. Also, the high expression of NF- $\mathrm{kB}$ within the cancer cells might be used for the eradication of selective cancer cells that could be regulated by the modulation of the NF- $\mathrm{KB}$ pathway [129].

Viable prostate cancer cells increase NF- $\mathrm{KB}$ translocation to the nucleus with subsequent enhancement of both activation of NF- $\mathrm{KB}$ transcription and induction of $\mathrm{NF}-\kappa \mathrm{B}$ responsive genes. This increase in NF- $\mathrm{\kappa B}$ expression may be related to the NF- $\mathrm{\kappa B}$ function as a transcription factor, which can explain the increase of cancer cells division [130]. NF- $\mathrm{KB}$ is highly expressed in actively proliferating prostate cancer. NF- $\kappa \mathrm{B}$ provides surface accessibility and preferred accumulation of antibody-conjugated Nano carriers through receptor-mediated endocytosis [131]. Conjugating a nanoparticle with appropriate surface molecules such as NF- $\mathrm{\kappa B}$ may trigger and control drug release properties and prolong drug release time [132]. The results from the conjugation experiment involving $\mathrm{NF}-\kappa \mathrm{B}$ and SC-514 demonstrated the possibilities of modulating the release profile by means of modifying the surface of the nanoparticles for higher encapsulation efficiency consistent with other studies. [133-136]. Drug delivery systems with high drug encapsulation efficiency and controlled release are of great importance in biomedical fields [137].

In addition, some membrane transport proteins maybe implicated in the endocytosis of PLGA nanoparticles in prostate cancer cells. These membrane transport proteins may play a role in PLGA nanoparticle endocytosis [138] in PC-3 and cord blood cells. The plasma membrane can be crossed by PLGA NPs with a diameter of $500-600 \mathrm{~nm}$ [139]. It appeared that the difference in nanoparticle sizes may cause the difference in nanoparticle retention between SC-514-PLGA-NF- $\mathrm{kBAb}$ nanoparticles and SC-514-PLGA nanoparticles. Physical characterization showed that the antibody unconjugated and conjugated particles were oval to spherical and within the size range of $200-250 \mathrm{~nm}$. This current study indicated that the average particle size slightly increased for antibody- 
conjugated nanoparticles SC-514-PLGA-NF- $\kappa$ BAb compared to the SC-514-PLGA. This implies that a hard decision needs to be made based on the preference for particle size and the length of time it takes to release SC-514 drug.

The SC-514 release from SC-514 PLGA nanoparticles was investigated using dialysis method. The principle was based on a change in the permeation rate of the small molecule across the dialysis membrane with the change in the free fraction (or fraction bound) inside the dialysis chamber $[140,141]$. The application of the dynamic dialysis method for determining release kinetics from nanoparticles seems to have grown in popularity, in part due to the willingness of investigators to ignore the demerits of dynamic dialysis method [142]. With the ever-increasing research efforts in the field of nanoparticles as drug delivery systems, it is critical to understand the limitations of this widely adopted dynamic dialysis method for determination of release kinetics. There are various scenarios where the interpretation of release data using dialysis can be either inaccurate or completely misleading. As shown in this study, consideration of the binding affinity of the drug to the nanoparticles, appropriate control experiments, and suitable mechanism-based mathematical treatment of the data should aid in the judicious use of the dialysis method for determination of the release kinetics from nanoparticles [143].

The dual barrier nature inherent in the dynamic dialysis method complicates data interpretation and may lead to incorrect conclusions regarding nanoparticle release half-lives. Although the need to consider the barrier properties of the dialysis membrane has long been recognized, there is an insufficient quantitative appreciation for the role of the driving force for drug transport across that membrane. Reversible Nano carrier binding of the released drug reduces the driving force for drug transport across the dialysis membrane leading to a slower overall apparent release rate [144]. This may lead to the conclusion that a given nanoparticle system will provide a sustained release in-vivo. However, this not always true.

Although the equilibrium dialysis method can achieve separation of nanoparticles from the surrounding solution, this method can produce misleading in-vitro release data. To date, no standardized technique for the assessment of drug release from Nano medicines has been issued by regulatory authorities. In view of the shortcomings of dialysis methods, pressure ultrafiltration has been proposed as an alternative dialysis method that can produce a release profile that is representative of the true distribution of the drug between the nanoparticle and the dispersing medium at any point in time [145].

A potential issue associated with the use of any of the physical separation methods is that the separation may be incomplete or inefficient. It is impossible to visually detect the presence of a small number of nanoparticles present in the filtrate or supernatant of a separated sample. However, their presence is likely to lead to significant measurement errors, particularly early in the release timescale when the concentration of drug in the carrier particles is high relative to that free in solution. The application of such separation methods is frequently reported in the drug delivery literature, however to our knowledge there has been no method proposed to validate the efficiency of separation of nanoparticles from the surrounding medium in which they are dispersed to produce a 'clean' sample of unbound drug. The human body is able to adapt to a little inefficiency between nanoparticles and surrounding medium because a research showed that a large amount of PLGA nanoparticles were present in the kidney and liver, without causing any morphological changes in respective tissues, even at a high dose of PLGA. This emphasizes the fact that PLGA nanoparticles are safe in the kidney and liver when they are used to deliver any incorporated drug [146].
The US-FDA has also recommended it as nontoxic and safe for human use. There is no report of its toxic effect on the kidney and liver [147]. This is consistent with the results from this study. PLGA polymer impacted the lowest amount of toxic effect on cord blood cells, followed by SC-514-PLGA-NF- $\kappa$ BAb, SC-514-PLGA-Fat, SC-514-PLGA, and then free SC-514 (Figure 16 and Figure 17). PLGA enhanced therapeutic potency even at low concentration of SC-514 drug released.

In-vivo treatment of PC-3 cells in a mouse model with SC-514PLGA-NF- $\kappa \mathrm{BAb}$ will potentially support the site-specific drug delivery ability of the formulation and therapeutic potential of formulated Nano carriers in the treatment of NF- $\kappa \mathrm{B}$-overexpressed prostate cancers. In this study, antibody-conjugated SC-514-loaded PLGA nanoparticles showed a promise in improving the tumor sitespecific delivery of the drug with a significant reduction of drugrelated toxicity (Figure 16 and Figure 17). SC-514-PLGA showed therapeutic improvement over free-SC-514, SC-514-PLGA-NF$\kappa \mathrm{BAb}$ and SC-514-PLGA-Fat on the first day of drug release to PC3 prostate cancer cells (Figure 18 and Figure 19). However, SC-514 drug release from SC-514-PLGA-NF- $\kappa$ BAb and SC-514-PLGA-Fat may be advantageous for prolonged and sustained drug release needed to reduce MDR in prostate cancer. Hence, SC-514-PLGAFat or SC-514-PLGA-NF- $\kappa$ BAb could be a preferential choice to deliver SC-514 drug more specifically in MDR-overexpressed prostate cancer cells.

During the first 7 days of cumulative drug release, free SC-514 had lower toxicity (most likely because of low solubility) than SC-514PLGA-NF- $\kappa \mathrm{BAb}$. However, after 7 days the toxicity of free SC-514 was higher than the toxicity of SC-514-PLGA-NF- $\kappa$ BAb (Figure 17). This is consistent with the results from our previous study that indicated higher anti-cancer activities for SC-514 at high concentrations [46].

The evaluation of the side effects of the nanoparticle systems compared to the free SC-514 may indicate apparent similar side effects based on cell viability study with cord blood cells (Figure 16 and Figure 17). However, a prolonged sustained release of SC-514 drug from SC-514-PLGA, SC-514-PLGA-NF- $\kappa \mathrm{BAb}$ and SC-514PLGA-Fat has therapeutic advantage to overcome MDR in prostate cancer. Specifically, PLGA-3-BPA + SC-514 nanoparticle treatment reduced the number of MDR PC-3 cells and MDR DU-145 cells significantly when compared to SC-514 and 3-BPA +SC-514 treatments.

The nanoparticle formulations have the potential to preferentially deliver SC-514 drug to the tumorigenic cells, causing reduction of SC-514 mediated toxicity due to its more site-specific distribution of drug to the target site. Further, due to sustained and controlled drug release from the formulation, much less free drug will reach the heart and other parts of body tissue to cause cardiac toxicity and systemic toxicity respectively. Thus, this formulation may offer future hope to deliver the drug to the target cancer tissue and minimize toxicity of the drug to normal tissue. However, the major limitation of this antibody-conjugated formulation such as SC-514PLGA-NF- $\mathrm{KBAb}$ is the saturation of cell surface target protein (antigen). Once the surface antigen proteins are saturated, the formulation would not be able to target the neoplastic cells only and prolong presence without its distribution in neoplastic cells, which may affect normal prostate cells [115].

Thus, the dose of SC-514-PLGA-NF-kBAb nanoparticle should be optimized before administration of formulation in-vivo. Hence, further studies including animal model studies and clinical trials are needed to optimize the dose of SC-514 in human subjects and to investigate the clinical efficacy of the formulation in the human prostate cancer patients. Efficient quantification of SC-514 drug could support optimization of SC-514 drug release for in-vitro and 
in-vivo studies. In this study, high-performance liquid chromatography (HPLC), LC/mass spectrometry (MS) and LC/tandem mass spectrometry (MS/MS) were utilized as the standard method to quantify SC-514 drug released from SC-514PLGA nanoparticles. HPLC and LC/MS have been widely used for biomedical analyses, in which chemical derivatization (a technique used in chemistry which converts a chemical compound into a product of similar chemical structure) is one of the most important methods to increase sensitivity and selectivity $[148,149]$.

LC-MS/MS offers improved levels of accuracy and reproducibility over traditional methods. LC-MS/MS has emerged as the latest technology utilized for drug release studies. However, this technology is not readily available to most researchers [150]. There is a need to investigate new methods for drug release studies. In this study, we investigated the use of other methods such as colony forming assay, transwell invasion and migration assay, and wound healing assay as alternative methods for drug release studies.

During the transwell assay, necessary precaution was taken to avoid washing off fixed cells from the membrane. The cell dilutions were worked out and the dishes were labeled appropriately. The experiment was conducted continuously to limit the total time, preventing adverse effects of $\mathrm{pH}$ and temperature changes. It is important to note that there are distinct differences between the transwell cell migration and the transwell cell invasion assays. The transwell cell migration assay measures the chemotactic capability of cells toward a chemo-attractant. The transwell cell invasion assay, however, measures both cell chemo taxis and the invasion of cells through extracellular matrix, a process that is commonly found in prostate cancer metastasis. In this study we utilized both transwell cell migration and invasion assay as an alternative method for LC/MS. The number of PC-3 cells that migrated was counted manually using a counter. Other studies utilized I-AbACUS, a software tool specifically designed to aid the analysis of the transwell assays that automatically and specifically recognized cells in images of stained membranes and provided the user with a suggested cell count.

Comparison between I-AbACUS and the standard technique for analysis of the transwell assay indicated that the manual count had an average error below 10\%. Although transwell and invasion migration assay, colony forming assay, and wound healing assay are techniques that have been used extensively in multiple research studies [151-154]. This current study is the first study that explored transwell and invasion migration assay, colony forming assay, and wound healing assay as a method of quantifying drug release.

The three alternative methods of quantifying SC-514 drug released from SC-514-PLGA nanoparticles discussed above did not show burst release like the LC-MS method. The LC-MS method consistently indicated the highest cumulative SC-514 drug released (Figure 3). The pattern of drug release was similar for all the three alternative methods without burst release (wound healing assay, colony forming assay, and transwell migration and invasion assays). The wound assay consistently indicated higher level of cumulative release compared to colony assay method and transwell method. Between day 9 and day 23 of drug release, there was a clear difference between the cumulative release levels of the three alternative methods: the highest release was observed in the wound assay method, followed by the colony assay then the transwell assay (Figure 3).

Dissolution of a drug is the rate determining step for oral absorption of the poorly water-soluble drugs and solubility is the basic requirement for the absorption of the drug. A proper selection of solubility enhancement method is the key to ensure the goals of a good formulation like good oral bioavailability, reduce dosage frequency and better patient compliance combined with a low cost of production. Selection of methods for solubility enhancement depends upon drug characteristics like solubility, chemical nature, melting point, absorption site, physical nature, pharmacokinetic behavior, dosage form requirement like tablet or capsule formulation, strength, immediate, or modified release, and regulatory requirements like maximum daily dose of any excipients and/or drug, approved excipients, and analytical accuracy [45].

although a reported study indicated that endocytosis of nanoparticles in primary cultured RCECs occurred mostly independent of clathrinand caveolin-1-mediated pathways, other proteins maybe involved in the endocytosis of PLGA nanoparticles in the PC-3 cells and cord blood cells. The internalization of poly (dl-lactide-co-glycolide, PLGA) nanoparticles in prostate cancer cells occurred by an endocytic process, regulated by availability of energy [138]. Inhibition of ATP energy in prostate cancer cells is expected to regulate the internalization of PLGA nanoparticles by the cells. Fluorescent cell uptake corroborated the receptor mediated endocytosis pathway, indicating the role of adenosine receptors in internalization of conjugated particles. This internalization was observed under confocal microscopy (Nikon A1R Confocal System w/SIM).

The higher uptake of the nanoparticles by prostate cancer cells than cord blood cells was confirmed with confocal microscopy (Figure 12). Cellular uptake of SC-514 was time dependent and occurred potentially via endocytosis mechanism. This study tested prostate cancer cells in-vitro with traditional free SC-514 in comparison with poly lactic co-glycolic acid nanoparticles carrying SC-514 (SC-514PLGA, SC-514-PLGA-NF-kBAb, and SC-514-PLGA-Fat).

Although, PLGA was conjugated with encapsulating parthenolide, a $\mathrm{NF}-\mathrm{\kappa B}$ inhibitor, in order to improve the selectivity and targeting of cancer cells while protecting the normal cells [155], this current study appears to be the first study to functionalize the surface of PLGA with NF- $\kappa$ B antibody or fats.

There is a high probability that NF-kB-conjugated PLGA nanoparticles and fat-conjugated PLGA nanoparticles containing SC-514 preferentially delivered encapsulated SC-514 drug to the prostate cancer cells. This site-specific delivery of the formulation to neoplastic cells would have minimal toxic effect on normal cells such as prostate cells and white blood cells.

The ligand conjugated nanoparticles further showed considerable potential in reduction of toxicity, a prominent side-effect of the drug. Since conjugation increases the size of nanoparticles [156] and smaller particles with large surface area are more soluble than larger particles with smaller surface area [45] that means SC-514-PLGA$\mathrm{NF}-\kappa \mathrm{BAb}$ and SC-514-PLGA-Fat nanoparticles will have a lower solubility than SC-514-PLGA because SC-514-PLGA- NF-KBAb and SC-514-PLGA-Fat nanoparticles were larger in size. The major consideration will be to determine whether increase solubility of SC-514 is more important than controlled prolonged drug release of SC-514 for multidrug resistance reduction in prostate cancer treatment.

Functionalized NPs reduce toxicity and side effects of drugs. Also, functionalize NP support crossing the biological barriers, such as the blood-brain barrier, and different cellular compartments, including the nucleus [157]. Functionalization enhances the properties and characteristics of nanoparticles through surface modification; and enables them to play a major role in the field of medicine. Nanoparticle drug delivery could be a promising new approach for personalized medicine. The optimized formulation was covalently conjugated to NF- $\mathrm{kB}$ antibody and fats and oils. Surface conjugation of the ligand was assessed by confocal microscopy.

Selectivity and cytotoxicity of the experimental nanoparticles were tested on human prostate cancer and cord blood cells utilizing MTT 
assay. The NF- $\mathrm{NB}$-conjugated and unconjugated nanoparticles were examined under a confocal microscope. In this study, we utilized confocal microscopy to investigate functionalized nanoparticles. Other techniques have been employed to investigate the functionalized NPs, including exclusion chromatography (SEC).

The properties of PLGA carrier-cargo system and release might be strongly influenced by the combination of factors, including the individual properties of loaded compounds, surface modification of the nanoparticles, and microenvironment. Thus, it is unlikely that a single nanoparticle formulation will be identified that is universally effective for the delivery of different compounds. The performance of anti-cancer agents used in cancer diagnoses and therapies are improved by enhanced cellular internalization of smart Nano carriers and controlled drug release. In this study, SC-514-PLGANF- $\kappa B A b$ nanoparticles improved the bioavailability and selective targeting of prostate cancer cells compared to free SC-514, thus holding promise as a drug delivery system to improve the cure rate of prostate cancer.

\section{Conclusion}

The results from this study will encourage the development of drug delivery systems for the local delivery of anti-cancer drugs. PLGA drug delivery system will be advantageous to decrease the concentration of administered SC-514 drug and the frequency of administration, and subsequently minimizing the adverse effects that are faced by prostate cancer patient during treatment. Findings from this study will contribute to the rational design of other drug delivery systems with high drug encapsulation efficiency and controlled release for treatment of various cancers.

\section{References}

1. Park TG. Degradation of poly (lactic-co-glycolic acid) microspheres: effect of copolymer composition (1995) Biomaterials 16: 1123-1130. https://doi.org/10.1016/01429612(95)93575-X

2. Jain RA. The manufacturing techniques of various drug loaded biodegradable poly (lactide-co-glycolide) (plga) devices (2000) Biomaterials 21: 2475-2490.

https://doi.org/10.1016/S0142-9612(00)00115-0

3. Sahoo SK, Panyam J, Prabha S and Labhasetwar V. Residual polyvinyl alcohol associated with poly (d,l-lactide-coglycolide) nanoparticles affects their physical properties and cellular uptake (2002) Journal of Controlled Release 82: 105 114. https://doi.org/10.1016/S0168-3659(02)00127-X

4. HansML and Lowman AM. Biodegradable nanoparticles for drug delivery and targeting (2002) Curr Opin Solid State Mater Sci 6: 319-327.

https://doi.org/10.1016/S1359-0286(02)00117-1.

5. Yingchoncharoen P, Kalinowski DS and Richardson DR. Lipid-based drug delivery systems in cancer therapy: what is available and what is yet to come (2016) Pharmacological Reviews 68: 701-787. https://doi.org/10.1124/pr.115.012070

6. Ulbrich K, Holá K, Šubr V, Bakandritsos A, Tuček J, et al. Targeted drug delivery with polymers and magnetic nanoparticles: covalent and noncovalent approaches, release control, and clinical studies (2016) Chemical Reviews 116: 5338-5431. https://doi.org/10.1021/acs.chemrev.5b00589

7. Siegal T. Which drug or drug delivery system can change clinical practice for brain tumor therapy? (2013) NeuroOncology 15: 656-669. https://doi.org/10.1093/neuonc/not016

8. Kamaly N, Yameen B, Wu J and Farokhzadm OC. Degradable controlled-release polymers and polymeric nanoparticles: mechanisms of controlling drug release (2016) Chemical Reviews 116: 2602-2663. https://doi.org/10.1021/acs.chemrev.5b00346
9. Nochos A, Douroumis D and Bouropoulos N. In-vitro release of bovine serum albumin from alginate/hpmc hydrogel beads (2008) Carbohydrate Polymers 74: 451-457. https://doi.org/10.1016/j.carbpol.2008.03.020

10. Makadia HK and Siegel SJ. poly lactic-co-glycolic acid (plga) as biodegradable controlled drug delivery carrier (2011) Polymers 3: 1377-1397. https://doi.org/10.3390/polym3031377

11. Chereddy KK, Vandermeulen G and Préat V. PLGA based drug delivery systems: Promising carriers for wound healing activity (2016) Wound Repair and Regeneration 24: 223-236. https://doi.org/10.1111/wrr.12404

12. Zhang E, Zhukova V, Semyonkin A, Osipova N, Malinovskaya Y, et al. Release kinetics of fluorescent dyes from PLGA nanoparticles in retinal blood vessels: In-vivo monitoring and ex vivo localization (2020) European Journal of Pharmaceutics and Biopharmaceutics 150: 131-142. https://doi.org/10.1016/j.ejpb.2020.03.006

13. Bobo D, Robinson KJ, Islam J, Thurecht KJ and Corrie SR. Nanoparticle-based medicines: a review of fda-approved materials and clinical trials to date (2016) Pharmaceutical Research. https://doi.org/10.1007/s11095-016-1958-5

14. Lü JM, Wang X, Marin-Muller C, Wang H, Lin PH, et al Current advances in research and clinical applications of plgabased nanotechnology (2009) Expert Review of Molecular Diagnostics 9: 325-341. https://doi.org/10.1586/erm.09.15

15. Shi J, Kantoff PW, Wooster R and Farokhzad OC. Cancer nanomedicine: Progress, challenges and opportunities (2017) Nature Reviews Cancer 17: 20-37.

https://doi.org/10.1038/nrc.2016.108

16. Welt FGP and Edelman ER. Adv Drug Delivery Rev Cell cycle regulation and control of angioplasty restenosis (1997) Advanced Drug Delivery Reviews 25: 299 https://doi.org/10.1016/s0169-409x(97)90003-x

17. Y, Wu X, Mi Y, Zhang B, Gu S, et al. PLGA nanoparticles for the oral delivery of nuciferine: Preparation, physicochemical characterization and in-vitro/in-vivo studies (2017) Drug Delivery 24: 443-451. https://doi.org/10.1080/10717544.2016.1261381

18. Duncan R. Nanomedicine gets clinical (2005) Materials Today 8: 16-17. https://doi.org/10.1016/S1369-7021(05)71032-4

19. Brigger I, Dubernet $C$ and Couvreur P. Nanoparticles in cancer therapy and diagnosis (2002) Advanced Drug Delivery Reviews 64: 24-36. https://doi.org/10.1016/S0169-409X(02)00044-3

20. Zhang $L$ and Webster TJ. Nanotechnology and nanomaterials: Promises for improved tissue regeneration (2009) Nano Today 4: 66-80. https://doi.org/10.1016/j.nantod.2008.10.014

21. Mei L, Zhang Z, Zhao L, Huang L, Yang XL, et al. Pharmaceutical nanotechnology for oral delivery of anticancer drugs (2013) Advanced Drug Delivery Reviews 65: 880-890. https://doi.org/10.1016/j.addr.2012.11.005

22. Van Vlerken LE, Vyas TK and Amiji MM. Poly (ethylene glycol)-modified nanocarriers for tumor-targeted and intracellular delivery (2007) Pharmaceutical Research 24: 1405-1414. https://doi.org/10.1007/s11095-007-9284-6

23. Musacchio T and Torchilin VP. Recent developments in lipidbased pharmaceutical nanocarriers (2011) Frontiers in Bioscience 16: 1388-1412. https://doi.org/10.2741/3795

24. Zhang J, Wang L, You X, Xian T, Wu J, et al. Nanoparticle Therapy for Prostate Cancer: Overview and Perspectives (2019) Current Topics in Medicinal Chemistry 19: 57-73. https://doi.org/10.2174/1568026619666190125145836

25. Ganju A, Yallapu MM, Khan S, Behrman SW, Chauhan SC, et al. Nanoways to overcome docetaxel resistance in prostate cancer (2014) Drug Resistance Updates 17: 13-23. https://doi.org/10.1016/j.drup.2014.04.001

26. Singh S, Sharma A and Robertson GP. Realizing the clinical potential of cancer nanotechnology by minimizing toxicologic 
and targeted delivery concerns (2012) Cancer Research 72: 5663-5668. https://doi.org/10.1158/0008-5472.CAN-12-1527

27. Arias JL. Drug targeting strategies in cancer treatment: an overview (2010) Mini-Reviews in Medicinal Chemistry 11:117. https://doi.org/10.2174/138955711793564024

28. Maeda $\mathrm{H}$, Nakamura $\mathrm{H}$ and Fang J. The EPR effect for macromolecular drug delivery to solid tumors: Improvement of tumor uptake, lowering of systemic toxicity, and distinct tumor imaging in-vivo (2013) Advanced Drug Delivery Reviews 65: 71-79.

https://doi.org/10.1016/j.addr.2012.10.002

29. Torchilin V. Tumor delivery of macromolecular drugs based on the EPR effect (2011) Advanced Drug Delivery Reviews 63: 131-135. https://doi.org/10.1016/j.addr.2010.03.011

30. Barenholz Y. Doxil® - The first FDA-approved nano-drug: Lessons learned (2012) Journal of Controlled Release 160: 117-134. https://doi.org/10.1016/j.jconrel.2012.03.020

31. Byrne JD, Betancourt $\mathrm{T}$ and Brannon-Peppas L. Active targeting schemes for nanoparticle systems in cancer therapeutics (2008) Advanced Drug Delivery Reviews 60: 1615-1626. https://doi.org/10.1016/j.addr.2008.08.005

32. Fenske DB and Cullis PR. Liposomal nanomedicines (2008) Expert Opinion on Drug Delivery 5: 25-44. https://doi.org/10.1517/17425247.5.1.25

33. Maurer N, Fenske DB and Cullis PR. Developments in liposomal drug delivery systems (2001) Expert Opinion on Biological Therapy 1: 923-947.

https://doi.org/10.1517/14712598.1.6.923

34. Zedan AH, Hansen TF, Assenholt J, Pleckaitis M, Madsen JS, et al. MicroRNA expression in tumour tissue and plasma in patients with newly diagnosed metastatic prostate cancer (2018) Tumor Biology 40. https://doi.org/10.1177/1010428318775864

35. Kita K and Dittrich C. Drug delivery vehicles with improved encapsulation efficiency: taking advantage of specific drugcarrier interactions (2011) Expert Opinion on Drug Delivery 8: 329-342. https://doi.org/10.1517/17425247.2011.553216

36. Qiu Y and Park K. Environment-sensitive hydrogels for drug delivery (2012) Advanced Drug Delivery Reviews 64: 49-60. https://doi.org/10.1016/j.addr.2012.09.024

37. Oh JK, Drumright R, Siegwart DJ and Matyjaszewski K. The development of microgels/nanogels for drug delivery applications (2008) Progress in Polymer Science (Oxford) 33: 448-477. https://doi.org/10.1016/i.progpolymsci.2008.01.002

38. Ning P, Lü S, Bai X, Wu X, Gao C, et al. High encapsulation and localized delivery of curcumin from an injectable hydrogel (2018) Materials Science and Engineering C 83: 121-129. https://doi.org/10.1016/j.msec.2017.11.022

39. Zhao J, Li Y and Wang M. Fabrication of robust transparent hydrogel with stretchable, self-healing, easily recyclable and adhesive properties and its application (2019) Materials Research Bulletin 112: 292-296.

https://doi.org/10.1016/j.materresbull.2018.12.033

40. Pooresmaeil $M$ and Namazi $H$. Preparation and characterization of polyvinyl alcohol $/ \beta$-cyclodextrin $/ \mathrm{GO}-\mathrm{Ag}$ nanocomposite with improved antibacterial and strength properties (2019) Polymers for Advanced Technologies 30: 447-456. https://doi.org/10.1002/pat.4484

41. Kankala RK, Kuthati Y, Sie HW, ShihHY, Lue SI, et al. Multi-laminated metal hydroxide nanocontainers for oralspecific delivery for bioavailability improvement and treatment of inflammatory paw edema in mice (2015) Journal of Colloid and Interface Science 458: 217-228. https://doi.org/10.1016/j.jcis.2015.07.044

42. Lee SH, Song JG and Han HK. Development of $\mathrm{pH}$-responsive organic-inorganic hybrid nanocomposites as an effective oral delivery system of protein drugs (2019) Journal of Controlled Release 311: 74-84. https://doi.org/10.1016/j.jconrel.2019.08.036
43. Vahed AT, Naimi-Jamal MR and Panahi L. Alginate-coated ZIF-8 metal-organic framework as a green and bioactive platform for controlled drug release (2019) Journal of Drug Delivery Science and Technology 49: 570-576. https://doi.org/10.1016/j.jddst.2018.12.022

44. Savjani KT, Gajjar AK and Savjani JK. Drug solubility: importance and enhancement techniques (2012) ISRN Pharmaceutics. https://doi.org/10.5402/2012/195727

45. Famuyiwa OT, Jebelli J, Diaka JKK and Asghar W. Interaction between 3-bromopyruvate and sc-514 in prostate cancer treatment (2018) Journal of Cancer Prevention and Current Research 9: 270-280.

https://doi.org/10.15406/jcpcr.2018.09.00367

46. Anwer MK, Mohammad M, Ezzeldin E, Fatima F, Alalaiwe A, et al. Preparation of sustained release apremilast-loaded PLGAlga nanoparticles: In-vitro characterization and in-vivo pharmacokinetic study in rats (2019) International Journal of Nanomedicine 2019: 1587-1595. https://doi.org/10.2147/IJN.S195048

47. Govender T, Stolnik S, Garnett MC, Illum L and Davis SS. PLGA nanoparticles prepared by nanoprecipitation: Drug loading and release studies of a water soluble drug (1999) Journal of Controlled Release 57: 171-185. https://doi.org/10.1016/S0168-3659(98)00116-3

48. Drummond DC, Noble CO, Guo Z, Hong K, Park JW, et al. Development of a highly active nanoliposomal irinotecan using a novel intraliposomal stabilization strategy (2006) Cancer Research 66: 3271-3277. https://doi.org/10.1158/0008-5472.CAN-05-4007

49. Johnston MJW, Semple SC, Klimuk SK, Edwards K, Eisenhardt ML, et al. Therapeutically optimized rates of drug release can be achieved by varying the drug-to-lipid ratio in liposomal vincristine formulations (2006) Biochimica et Biophysica Acta (BBA) Biomembranes 1758: 55-64. https://doi.org/10.1016/j.bbamem.2006.01.009

50. Joguparthi $\mathrm{V}$ and Anderson BD. Liposomal delivery of hydrophobic weak acids: Enhancement of drug retention using a high intraliposomal $\mathrm{pH}$ (2008) Journal of Pharmaceutical Sciences 97: 433-454. https://doi.org/10.1002/jps.21135

51. Washington C. Drug release from microdisperse systems: a critical review (1990) International Journal of Pharmaceutics 58: 1-12. https://doi.org/10.1016/0378-5173(90)90280-H

52. Herman EH, Vicl JA, Rahmar A, Schein PS and Ferrara JV. Prevention of chronic doxorubicin cardiotoxicity in beagles by liposomal encapsulation (1983) Cancer Research 43: 54272432.

53. Barenholz Y. Relevancy of drug loading to liposomal formulation therapeutic efficacy (2003) Journal of Liposome Research 13: 1-8. https://doi.org/10.1081/LPR-120017482

54. - Washington $\mathrm{C}$ and Koosha F. Drug release from microparticulates; deconvolution of measurement errors (1990) International Journal of Pharmaceutics 59: 79-82 https://doi.org/10.1016/0378-5173(90)90067-E

55. Lorenzo CA and Concheiro A. Smart drug delivery systems: from fundamentals to the clinic (2014) Chemical Communications 50: 7743:7765. https://doi.org/10.1039/c4cc01429d

56. Bao B, Thakur A, Li Y, Ahmad A, Azmi AS, et al. The immunological contribution of $\mathrm{nf}-\kappa \mathrm{b}$ within the tumor microenvironment: a potential protective role of zinc as an anti-tumor agent (2012) Biochimica et Biophysica Acta Reviews on Cancer 1825: 160-172. https://doi.org/10.1016/j.bbcan.2011.11.002

57. Park $M$ and Hong J. Roles of nf-kb in cancer and inflammatory diseases and their therapeutic approaches (2016) Cells 5: 15. https://doi.org/10.3390/cells5020015

58. Zhou J, Ching YQ and Chng WJ. Aberrant nuclear factorkappa B activity in acute myeloid Leukemia: From molecular 
pathogenesis to therapeutic target (2015) Oncotarget 6: 54905500. https://doi.org/10.18632/oncotarget.3545

59. deGraffenried LA, Chandrasekar B, Friedrichs WE, Donzis E, Silva J, et al. NF- $\mathrm{KB}$ inhibition markedly enhances sensitivity of resistant breast cancer tumor cells to tamoxifen (2004) Annals of Oncology 15: 885-890.

https://doi.org/10.1093/annonc/mdh232

60. Crowell JA, Steele VE, Sigman CC and Fay JR. Is inducible nitric oxide synthase a target for chemoprevention? (2003) Molecular Cancer Therapeutics 2: 815-823.

61. Pautz A, Art J, Hahn S, Nowag S, Voss C, et al. Regulation of the expression of inducible nitric oxide synthase (2010) Nitric Oxide - Biology and Chemistry 23: 75-93. https://doi.org/10.1016/j.niox.2010.04.007

62. Dolcet X, Llobet D, Pallares J and Matias-Guiu X. NF-kB in development and progression of human cancer (2005) Virchows Archiv 446: 475-482. https://doi.org/10.1007/s00428-005-1264-9

63. SA, Zaitseva L, Langa S, Bowles KM and MacEwan DJ. Flip regulation of ho-1 and tnf signalling in human acute myeloid leukemia provides a unique secondary anti-apoptotic mechanism (2010) Oncotarget 1: 359-366. https://doi.org/10.18632/oncotarget.168

64. Gyrd-Hansen M and Meier P. IAPs: From caspase inhibitors to modulators of NF- $\kappa B$, inflammation and cancer (2010) Nature Reviews Cancer 10: 561-574. https://doi.org/10.1038/nrc2889

65. Li X, Abdel-Mageed AB, Mondal D and Kandil E. The nuclear factor kappa-B signaling pathway as a therapeutic target against thyroid cancers (2013) Thyroid 23: 209-218. https://doi.org/10.1089/thy.2012.0237

66. Carbone $\mathrm{C}$ and Melisi D. NF- $\mathrm{\kappa B}$ as a target for pancreatic cancer therapy (2012) Expert Opinion on Therapeutic Targets 16: 1-10. https://doi.org/10.1517/14728222.2011.645806

67. Jain G, Cronauer MV, Schrader M, Möller P and Marienfeld RB. NF- $\mathrm{KB}$ signaling in prostate cancer: A promising therapeutic target? (2012) World Journal of Urology 30: 303 310. https://doi.org/10.1007/s00345-011-0792-y

68. Hjortso $\mathrm{M}$ and Andersen M. The expression, function and targeting of haem oxygenase-1 in cancer (2014) Current Cancer Drug Targets 14: 337-347. https://doi.org/10.2174/1568009614666140320111306

69. Jeney V, Balla J, Yachie A, Varga Z, Vercellotti GM, et al. Pro-oxidant and cytotoxic effects of circulating heme (2002) Blood 100: 879-887. https://doi.org/10.1182/blood.V100.3.879

70. Caballero B. The global epidemic of obesity: An overview (2007) Epidemiologic Reviews 29: 1-5. https://doi.org/10.1093/epirev/mxm012

71. Ogden CL, Carroll MD, Kit BK and Flegal KM. Prevalence of obesity in the United States, 2009-2010 (2012b) NCHS Data Brief 82: 1-8

72. Hales CM, Carroll MD, Fryar CD and Ogden CL. Prevalence of obesity among adults and youth: united states, 2015-2016 (2017) NCHS Data Brief 288: 1-8

73. Flegal KM, Kruszon-Moran D, Carroll MD, Fryar CD and Ogden CL. Trends in obesity among adults in the United States, 2005 to 2014 (2016) JAMA - Journal of the American Medical Association 315: 2284-2291. https://doi.org/10.1001/jama.2016.6458

74. Chooi YC, Ding C and Magkos F. The epidemiology of obesity (2019) Metabolism: Clinical and Experimental 92: 610. https://doi.org/10.1016/j.metabol.2018.09.005

75. Helmchen LA and Henderson RM. Changes in the distribution of body mass index of white US men, 1890-2000 (2004) Annals of Human Biology 31: 174-181. https://doi.org/10.1080/03014460410001663434

76. Flegal KM, Carroll MD, Ogden CL and Johnson CL. Prevalence and trends in obesity among US adults, 1999-2000 (2002) JAMA 288: 1723-1727. https://doi.org/10.1001/jama.288.14.1723
77. Flegal KM, Carroll MD, Ogden CL and Curtin LR. Prevalence and trends in obesity among US adults, 1999-2008 (2010) JAMA. https://doi.org/10.1001/jama.2009.2014

78. Ogden CL, Carroll MD, Curtin LR, McDowell MA, Tabak CJ, et al. Prevalence of overweight and obesity in the United States, 1999-2004 (2006) JAMA 295: 1549-1555. https://doi.org/10.1001/jama.295.13.1549

79. Flegal KM, Carroll D, Kit BK and Ogden CL. Prevalence of obesity and trends in the distribution of body mass index among US adults, 1999-2010 (2012) JAMA 307: 491-497. https://doi.org/10.1001/jama.2012.39

80. Hedley AA, Ogden CL, Johnson CL, Carroll MD, Curtin LR, et al. Prevalence of overweight and obesity among US children, adolescents, and adults, 1999-2002 (2004) Journal of the American Medical Association 291: 2847-2850. https://doi.org/10.1001/jama.291.23.2847

81. Ogden CL, Carroll MD, Kit BK and Flegal KM. Prevalence of obesity and trends in body mass index among US children and adolescents, 1999-2010 (2012a) JAMA 307: 483-490. https://doi.org/10.1001/jama.2012.40

82. McAllister EJ, Dhurandhar NV, Keith SW, Aronne LJ, Barger $\mathrm{J}$, et al. Ten putative contributors to the obesity epidemic (2009) Critical Reviews in Food Science and Nutrition 49: 868-913. https://doi.org/10.1080/10408390903372599

83. Ogden CL, Fakhouri TH, Carroll MD, Hales CM, Fryar CD, et al. Prevalence of Obesity Among Adults, by Household Income and Education - United States, 2011-2014 (2017) MMWR Morbidity and Mortality Weekly Report 66: 13691373. https://doi.org/10.15585/mmwr.mm6650a1

84. Amling CL, Kane CJ, Riffenburgh RH, Ward JF, Roberts JL, et al. Relationship between obesity and race in predicting adverse pathologic variables in patients undergoing radical prostatectomy (2001) Urology 58: 723-728. https://doi.org/10.1016/s0090-4295(01)01373-5

85. Mallah KN, DiBlasio CJ, Rhee AC, Scardino PT and Kattan MW. Body mass index is weakly associated with, and not a helpful predictor of, disease progression in men with clinically localized prostate carcinoma treated with radical prostatectomy (2005) Cancer 103: 2030-2034. https://doi.org/10.1002/cncr.20991

86. Yamamoto $\mathrm{H}$, Kuno $\mathrm{Y}$, Sugimoto $\mathrm{S}$, Takeuchi $\mathrm{H}$ and Kawashima Y. Surface-modified PLGA nanosphere with chitosan improved pulmonary delivery of calcitonin by mucoadhesion and opening of the intercellular tight junctions (2005) J of Controlled Release 102: 373-381. https://doi.org/10.1016/j.jconrel.2004.10.010

87. Prego C, García M, Torres D and Alonso MJ. Transmucosal macromolecular drug delivery (2005) J of Controlled Release 101: 151-162. https://doi.org/10.1016/j.jconrel.2004.07.030

88. -Stella B, Arpicco S, Peracchia MT, Desmaële D, Hoebeke J, et al. Design of folic acid-conjugated nanoparticles for drug targeting (2000) J of Pharma Sci. 89: 1452-1464 https://doi.org/10.1002/1520-6017(200011)89:11<1452::AIDJPS8 $>3.0 . \mathrm{CO} ; 2-\mathrm{P}$

89. Zhang N, Chittasupho C, Duangrat C, Siahaan TJ and Berkland C. PLGA nanoparticle-peptide conjugate effectively targets intercellular cell-adhesion molecule-1 (2008) Bioconjugate Chem 19: 145-152. https://doi.org/10.1021/bc700227z

90. Magenheim B, Levy MY and Benita S. A new in-vitro technique for the evaluation of drug release profile from colloidal carriers - ultrafiltration technique at low pressure (1993) International J of Pharmaceutics 94: 115-123. https://doi.org/10.1016/0378-5173(93)90015-8

91. Douer D. Efficacy and safety of vincristine sulfate liposome injection in the treatment of adult acute lymphocytic leukemia (2016) The Oncologist 21: 840-847.

https://doi.org/10.1634/theoncologist.2015-0391 
92. Wang D, Kong L, Wang J, He X, Li X, et al. Polymyxin E sulfate-loaded liposome for intravenous use: Preparation, lyophilization, and toxicity assessment in-vivo (2009) PDA Journal of Pharmaceutical Science and Technology 63: 159167.

93. Cui J, Li C, Deng Y, Wang Y and Wang W. Freeze-drying of liposomes using tertiary butyl alcohol/water cosolvent systems (2006) International Journal of Pharmaceutics 312: 131-136. https://doi.org/10.1016/j.ijpharm.2006.01.004

94. Boyd BJ. Characterisation of drug release from cubosomes using the pressure ultrafiltration method (2003) International $\mathbf{J}$ of Pharmaceutics 260: 239-247.

https://doi.org/10.1016/S0378-5173(03)00262-X

95. Zhang YV, Wei B, Zhu Y, Zhang Y and Bluth MH. Liquid Chromatography-Tandem Mass Spectrometry: An Emerging Technology in the Toxicology Laboratory (2016) Clinics in Laboratory Medicine 36: 635-661. https://doi.org/10.1016/j.cll.2016.07.001

96. Jones $\mathrm{G}$ and Kaufmann M. Vitamin D metabolite profiling using liquid chromatography-tandem mass spectrometry (LCMS/MS) (2016) J of Steroid Biochem and Mol Biology 164: 110-114. https://doi.org/10.1016/j.jsbmb.2015.09.026

97. Yadav P, Rath G, Sharma G, Singh R and Goyal AK Polysorbate 80 coated solid lipid nanoparticles for the delivery of temozolomide into the brain (2018) The Open Pharmacology Journal 8: 21-28. https://doi.org/10.2174/1874143601808010021

98. Li B, Wang X, Liu W and Xue Q. Tribochemistry and antiwear mechanism of organic-inorganic nanoparticles as lubricant additives (2006) Tribology Letters 22: 79-84. https://doi.org/10.1007/s11249-005-9002-7

99. Jifen $\mathrm{W}$, Wensheng $\mathrm{Z}$ and Guifen J. Preparation and tribological properties of tungsten disulfide hollow spheres assisted by methyltrioctylammonium chloride (2010) Tribology International 43: 1650-1658. https://doi.org/10.1016/j.triboint.2010.03.012

100. Yang G Bin, Chai ST, Xiong XJ, Zhang SM, Yu LG, et al. Preparation and tribological properties of surface modified $\mathrm{Cu}$ nanoparticles (2012) Transactions of Nonferrous Metals Society of China 22: 366-372. https://doi.org/10.1016/S1003$\underline{6326(11) 61185-0}$

101. Chen Y, Zhang Y, Zhang S, Yu L, Zhang P, et al. Preparation of nickel-based nanolubricants via a facile in situ one-step route and investigation of their tribological properties (2013) Tribology Letters 51: 73-83. https://doi.org/10.1007/s11249013-0148-4

102. Xiao-kun M, Lee NH, Oh HJ, Kim JW, Rhee CK, et al. Surface modification and characterization of highly dispersed silica nanoparticles by a cationic surfactant (2010) Colloids and Surfaces A: Physicochemical and Engineering Aspects 358: 172-176. https://doi.org/10.1016/j.colsurfa.2010.01.051

103. Ishii F and Nagasaka Y. Simple and Convenient Method for Estimation of Marker Entrapped in Liposomes (2001) Journal of Dispersion Science and Technology 22: 970-101. https://doi.org/10.1081/DIS-100102684

104. Marshall J. Transwell $§$ invasion assays (2011) Methods in Molecular Biology 769: 97-110. https://doi.org/10.1007/978-1-61779-207-6_8

105. Bian Y, Du Y, Wang R, Chen N, Du X, et al. A comparative study of HAMSCs/HBMSCs transwell and mixed coculture systems (2019) IUBMB Life 71: 1048-1055. https://doi.org/10.1002/iub.2074

106. Li C, Zheng J, Chen S, Huang B, Li G, et al. RRM2 promotes the progression of human glioblastoma (2018) Journal of Cellular Physiology 233: 6759-6767. https://doi.org/10.1002/jcp.26529

107. Schachner M, Wortham KA, Ryberg MZ, Dorfman S and Campbell GLM. Brain cell surface antigens detected by anticorpus callosum antiserum (1977) Brain Research 127: 8797. https://doi.org/10.1016/0162-0134(86)80048-4

108. Famuyiwa TO. A new approach for preparing sc-514 loaded plga particles by single emulsion method (2019) Journal of Medical Pharmaceutical and Allied Sciences 8: 2367-2380. https://doi.org/10.22270/jmpas.v8i6.872

109. Alfarouk KO, Stock CM, Taylor S, Walsh M, Muddathir AK, et al. Resistance to cancer chemotherapy: Failure in drug response from ADME to P-gp (2015) Cancer Cell International 15. https://doi.org/10.1186/s12935-015-0221-1

110. Ruman U, Fakurazi S, Masarudin MJ and Hussein MZ. Nanocarrier-based therapeutics and theranostics drug delivery systems for next generation of liver cancer nanodrug modalities (2020) International Journal of Nanomedicine 2020: 1437-1456. https://doi.org/10.2147/IJN.S236927

111. Masood F. Polymeric nanoparticles for targeted drug delivery system for cancer therapy (2016) Materials Science and Engineering C 60: 569-578. https://doi.org/10.1016/i.msec.2015.11.067

112. Kang B, Zheng MB, Song P, Chen AP, Wei JW, et al. Subcellular-Scale Drug Transport via Ultrasound-Degradable Mesoporous Nanosilicon to Bypass Cancer Drug Resistance (2017) Small 13. https://doi.org/10.1002/smll.201604228

113. Mondal L, Mukherjee B, Das K, Bhattacharya S, Dutta D, et al. CD-340 functionalized doxorubicin-loaded nanoparticle induces apoptosis and reduces tumor volume along with drugrelated cardiotoxicity in mice (2019) International Journal of Nanomedicine 14: 8073-8094. https://doi.org/10.2147/IJN.S220740

114. Abd Ellah NH and Abouelmagd SA. Surface functionalization of polymeric nanoparticles for tumor drug delivery: approaches and challenges (2017) Expert Opinion on Drug Delivery 14: 201-214.

https://doi.org/10.1080/17425247.2016.1213238

115. Urimi D, Agrawal AK, Kushwah V and Jain S. Polyglutamic Acid Functionalization of Chitosan Nanoparticles Enhances the Therapeutic Efficacy of Insulin Following Oral Administration (2019) AAPS PharmSciTech 20. https://doi.org/10.1208/s12249-019-1330-2

116. Swami R, Singh I, Jeengar MK, Naidu VGM, Khan W, et al. Adenosine conjugated lipidic nanoparticles for enhanced tumor targeting (2015) International Journal of Pharmaceutics 486: 287-296. https://doi.org/10.1016/j.ijpharm.2015.03.065

117. Song CX, Labhasetwar V, Murphy H, Qu X, Humphrey WR, et al. Formulation and characterization of biodegradable nanoparticles for intravascular local drug delivery (1997) Journal of Controlled Release 43: 197-212. https://doi.org/10.1016/S0168-3659(96)01484-8

118. Azevedo CRD, Stosch VM, Costa MS, Ramos AM, Cardoso MM, et al. Modeling of the burst release from PLGA micro and nanoparticles as function of physicochemical parameters and formulation characteristics (2017) International Journal of Pharmaceutics 532: 229-240. https://doi.org/10.1016/j.ijpharm.2017.08.118

119. Maulvi FA, Patil RJ, Desai AR, Shukla MR, Vaidya RJ, et al. Effect of gold nanoparticles on timolol uptake and its release kinetics from contact lenses: In-vitro and in-vivo evaluation (2019) Acta Biomaterialia 86: 350-362. https://doi.org/10.1016/j.actbio.2019.01.004

120. Borghi A, Foa E, Balossino R, Migliavacca F and Dubini G. Modelling drug elution from stents: Effects of reversible binding in the vascular wall and degradable polymeric matrix (2008) Comp Meth Biomech Biomed Eng 11: 367-377. https://doi.org/10.1080/10255840801887555

121. Huang $\mathrm{X}$ and Brazel CS. On the importance and mechanisms of burst release in matrix-controlled drug delivery systems (2001) J Controlled Release 73: 121-136. https://doi.org/10.1016/S0168-3659(01)00248-6 
122. Loew S, Fahr A and May S. Modeling the Release Kinetics of poorly water-soluble drug molecules from liposomal nanocarriers (2011) J Drug Delivery. https://doi.org/10.1155/2011/376548

123. Zeng $\mathrm{L}, \mathrm{An} \mathrm{L}$ and $\mathrm{Wu} \mathrm{X}$. Modeling drug-carrier interaction in the drug release from nanocarriers (2011) J Drug Delivery. https://doi.org/10.1155/2011/370308

124. Jelvehgari M, Valizadeh $\mathrm{H}$, Rezapour M and Nokhodchi A. Control of encapsulation efficiency in polymeric microparticle system of tolmetin (2010) Pharm Develop Techn 15: 71-79. https://doi.org/10.3109/10837450903002173

125. Yeo Y and Park K. Control of encapsulation efficiency and initial burst in polymeric microparticle systems (2004) Archives of Pharmacal Research.

126. Shukla S, MacLennan GT, Fu P, Patel J, Marengo SR, et al. Nuclear factor- $\mathrm{kB} / \mathrm{p} 65$ (Rel A) is constitutively activated in human prostate adenocarcinoma and correlates with disease progression (2004) Neoplasia 6: 390-400. https://doi.org/10.1593/neo.04112

127. Ghantous A, Sinjab A, Herceg $Z$ and Darwiche N. Parthenolide: From plant shoots to cancer roots (2013) Drug Discovery today 18: 894-905. https://doi.org/10.1016/i.drudis.2013.05.005

128. Pacifico F and Leonardi A. NF- $\mathrm{KB}$ in solid tumors (2006) Biochemical Pharmacology 72: 1142-1152. https://doi.org/10.1016/j.bcp.2006.07.032

129. Karin M and Greten FR. NF- $\mathrm{kB}$ : Linking inflammation and immunity to cancer development and progression (2005) Nature Reviews Immunology. https://doi.org/10.1038/nri1703

130. Hua X, Tan S, Bandara HMHN, Fu Y, Liu S, et al. Externally controlled triggered-release of drug from PLGA micro and nanoparticles (2014) PLoS ONE.

131. Bhagav P, Upadhyay H and Chandran S. Brimonidine tartrateeudragit long-acting nanoparticles: Formulation, optimization, in-vitro and in-vivo evaluation (2011) AAPS PharmSciTech. https://doi.org/10.1208/s12249-011-9675-1

132. Ünal S, Aktaş Y, Benito JM and Bilensoy E. Cyclodextrin nanoparticle bound oral camptothecin for colorectal cancer: Formulation development and optimization (2020) Inte J Pharma 584: 119468 https://doi.org/10.1016/j.ijpharm.2020.119468

133. Kaleemuddin $M$ and Srinivas P. Lyophilized oral sustained release polymeric nanoparticles of nateglinide (2013) AAPS PharmSciTech. https://doi.org/10.1208/s12249-012-9887-z

134. Sethi M, Sukumar R, Karve S, Werner ME, Wang EC, et al. Effect of drug release kinetics on nanoparticle therapeutic efficacy and toxicity (2014) Nanoscale https://doi.org/10.1039/c3nr05961h

135. Song B. Lotus leaf-inspired design of calcium alginate particles with superhigh drug encapsulation efficiency and $\mathrm{pH}$ responsive release (2018) Colloids and Surfaces B: Biointerfaces 172: 464-470. https://doi.org/10.1016/j.colsurfb.2018.09.001

136. Qaddoumi MG, Gukasyan HJ, Davda J, Labhasetwar V, Kim $\mathrm{KJ}$, et al. Clathrin and caveolin-1 expression in primary pigmented rabbit conjunctival epithelial cells: Role in PLGA nanoparticle endocytosis (2003) Molecular Vision.

137. Palocci C, Valletta A, Chronopoulou L, Donati L, Bramosanti $\mathrm{M}$, et al. Endocytic pathways involved in PLGA nanoparticle uptake by grapevine cells and role of cell wall and membrane in size selection (2017) Plant Cell Reports. https://doi.org/10.1007/s00299-017-2206-0

138. Meyer MC and Guttman DE. Dynamic dialysis as a method for studying protein binding I: Factors affecting the kinetics of dialysis through a cellophane membrane (1970a) J Pharma Sci 59: 33-38. https://doi.org/10.1002/jps.2600590104

139. Meyer MC and Guttman DE. Dynamic dialysis as a method for studying protein binding II: Evaluation of the method with a number of binding systems (1970b) J Pharma Sci 59: 39-48. https://doi.org/10.1002/jps.2600590105

140. Zambito Y, Pedreschi E and Di Colo G. Is dialysis a reliable method for studying drug release from nanoparticulate systems? - A case study (2012) Int J Pharma 434: 28-34. https://doi.org/10.1016/j.ijpharm.2012.05.020

141. Khaira R, Sharma J and Saini V. Development and characterization of nanoparticles for the delivery of gemcitabine hydrochloride (2014) The Scientific World Journal. https://doi.org/10.1155/2014/560962

142. Modi S and Anderson BD. Determination of drug release kinetics from nanoparticles: Overcoming pitfalls of the dynamic dialysis method (2013) Molecular Pharmaceutics. https://doi.org/10.1021/mp400154a

143. Wallace SJ, Li J, Nation RL and Boyd BJ. Drug release from nanomedicines: Selection of appropriate encapsulation and release methodology (2012) Drug Delivery and Translational Research. https://doi.org/10.1007/s13346-012-0064-4

144. Semete B, Booysen L, Lemmer Y, Kalombo L, Katata L, et al. In-vivo evaluation of the biodistribution and safety of PLGA nanoparticles as drug delivery systems (2010) Nanomedicine: Nanotechnology, Biology, and Medicine 6: 662-671. https://doi.org/10.1016/j.nano.2010.02.002

145. Navarro SM, Morgan TW, Astete CE, Stout RW, Coulon D, et al. Biodistribution and toxicity of orally administered poly (lactic-co-glycolic) acid nanoparticles to F344 rats for 21 days (2016) Nanomedicine 11: 1653-1669. https://doi.org/10.2217/nnm-2016-0022

146. Niessen WMA. Liquid chromatography | Mass spectrometry (2019) In Encyclopedia of Analytical Science https://doi.org/10.1016/B978-0-12-409547-2.142131

147. Perreault H and Lattová E. Mass spectrometry (2019) In Comprehensive Biotechnology 1: 679-687. https://doi.org/10.1016/B978-0-444-64046-8.00039-2

148. Berthiller F, Werner U, Sulyok M, Krska R, Hauser MT, et al. Liquid chromatography coupled to tandem mass spectrometry (LC-MS/MS) determination of phase II metabolites of the mycotoxin zearalenone in the model plant Arabidopsis thaliana (2006) Food Additives and Contaminants 23: 1194-1200. https://doi.org/10.1080/02652030600778728

149. van de Merbel AF, van der Horst G, Buijs JT and van der Pluijm G. Protocols for migration and invasion studies in prostate cancer (2018) In Methods in Molecular Biology 1786: 67-79. https://doi.org/10.1007/978-1-4939-7845-8 4

150. Karbarz M, Mytych J, Solek P, Stawarczyk K, TabeckaLonczynska $\mathrm{A}$, et al. Cereal grass juice in wound healing: hormesis and cell-survival in normal fibroblasts, in contrast to toxic events in cancer cells (2019) Journal of Physiology and Pharmacology : An Official Journal of the Polish Physiological Society 70: 595-604. https://doi.org/10.26402/jpp.2019.4.10

151. Gupta A, Behl T, Heer HR, Deshmukh R and Sharma PL. Mdm2-P53 interaction inhibitor with cisplatin enhances apoptosis in colon and prostate cancer cells in-vitro (2019) Asian Pacific Journal of Cancer Prevention 20: 3341-3351. https://doi.org/10.31557/APJCP.2019.20.11.3341

152. Collak FK, Demir U and Sagir F. YAP1 Is Involved in Tumorigenic Properties of Prostate Cancer Cells (2020) Pathology and Oncology Research 26: 867-876. https://doi.org/10.1007/s12253-019-00634-Z

153. Darwish NHE, Sudha T, Godugu K, Bharali DJ, Elbaz O, et al. Novel targeted nano-parthenolide molecule against NF-kB in acute myeloid leukemia (2019) Molecules 24: 2103. https://doi.org/10.3390/molecules24112103

154. Zarabi MF, Farhangi A, Mazdeh SK, Ansarian Z, Zare D, et al. Synthesis of gold nanoparticles coated with aspartic acid and their conjugation with FVIII protein and FVIII antibody (2014) Indian Journal of Clinical Biochemistry 29: 154-160. https://doi.org/10.1007/s12291-013-0323-2 
155. Adamo G, Campora S and Ghersi G. Functionalization of nanoparticles in specific targeting and mechanism release (2017) In Nanostructures for Novel Therapy: Synthesis, Characterization and Applications 57-80. https://doi.org/10.1016/B978-0-323-46142-9.00003-7

156. Thiruppathi R, Mishra S, Ganapathy, Padmanabhan P and Gulyás B. Nanoparticle functionalization and its potentials for molecular imaging (2017) Advanced Science 4 https://doi.org/10.1002/advs.201600279

157. Preecha $P$ and Jettanasen J. Investigation of functionalized silicon nanoparticles by size exclusion chromatography (2017) Materials Research Express 4. https://doi.org/10.1088/2053$\underline{1591 / \mathrm{a} 6638}$ 